\title{
Lethal Images:
}

\section{Analyzing Extremist Visual Propaganda from ISIS and Beyond}

\section{INTRODUCTION}

Violent extremist actors are common producers of propaganda, ${ }^{1}$ using "interpretive frameworks" to shape audience's perceptions with the purpose of generating sympathy, fostering support for violent action, and mobilizing recruits for their cause (Ingram 2017). A growing literature analyses how extremist propaganda is constructed to promote radicalization, focusing largely on language (both written and spoken) in empirical research (e.g. Reicher et al. 2005; Boussalis \& Coan 2015; Baele 2016; Ingram 2016). Images, by contrast, have initially garnered less attention in the literature; as Dauber and Winkler (2014:13) noted, research had, "for the most part, placed a clear emphasis on understanding the words contained in the groups' messages rather than images". Yet pictures can be “powerful tools in a social movement's arsenal” (Rohlinger \& Klein 2012: 172) and have now a prominent role in violent actors' outreach, mirroring the much broader rise of visual communication in society at large. ${ }^{2}$ Evidence of extremist imagery are, among others, the graphic appearance of several US-based anti-abortion groups' websites, ${ }^{3}$ or the now common practice for Salafi-jihadist groups to disseminate videos and image-loaded magazines, ${ }^{4}$ a practice recently perfected by the so-called Islamic State's (IS).

IS' extensive use of visual imagery has over the past few years sparkled intense interest, correcting the initial bias in favor of language. General overviews of IS' media effort increasingly dedicate space to the group's visual dimension (e.g. Milton 2016), and more focused studies highlight some of the organization's favorite visual tactics, such as its use of iconic imagery (e.g. Wignell, Tan \& O'Halloran 2017) or its repetition of particular tropes (Winkler et al. 2016; Winkler et al. 2018; El Damanhoury \& Winkler 2018). This stimulating line of research has encouraged scholars to investigate how other organizations use images, both within Salafi-Jihadism (e.g. Dauber 2014 on Al-Qaeda) and beyond (e.g. Waltman 2014). This rapidly expanding field, while advancing knowledge in significant ways, nonetheless suffers from a series of limitations: many are essentially descriptive, and the theoretical contributions of the more sophisticated pieces remain disjointed and case-specific. Efforts to create unity among scholars, either through edited volumes (e.g. Winkler \& Dauber 2014) or through in-depth theorizations (e.g. Bolt 2012 for an early attempt), have not yet resulted in the enunciation of a coherent theoretical framework conceptualizing violent extremists' use of images in propaganda.

Our paper aims to provide such a framework, building on the abovementioned work and integrating it with existing research on visual communication in various disciplines. This allows us to explain how already identified

\footnotetext{
${ }^{1}$ Although "critics differ in the elasticity of the definition that they would ascribe to the word 'propaganda"' (O'Shaughnessy 2000: 29), propaganda can be broadly understood as consisting of specific constructs and narratives used to convey a groups' message, with the aim of shaping audience's perceptions and behaviors in intended ways.

${ }^{2}$ For an early analysis, read Barthes 1961.

${ }^{3}$ E.g. https://www.armyofgod.com/.

${ }^{4}$ See https://ds-drupal.haverford.edu/aqsi/resources/jihadi-magazines.
} 
aspects such as symbolism or the repetition of particular visual tropes interact together and with other less-studied components, which in turn allows us to develop a portable method for the systematic empirical study of this kind of imagery across cases.

We proceed in three main steps. We begin with a multidisciplinary review of the literature examining images' potential to convey meaning and elicit emotions. ${ }^{5}$ Second, we develop a theoretical framework that articulates these effects in a conceptualization of the role played by extremist visual propaganda in radicalization dynamics. Specifically, we expose the interplay between two logics: a static one based on each group's favored "visual style", and a dynamic one based on the group's adjustments of this visual style in response to on the ground developments. Third, we transpose this framework into a specific and replicable method for the study of violent groups' visual propaganda, and apply this method to evaluate the use of images by IS in its Dabiq and Rumiyah magazines. While primarily intended as an illustrative example of our theory and method, this application of our framework nonetheless allows us to reveal the main characteristics of IS' visual style when it comes to the group's communication to Western audiences (such as its emphasis on the ingroup, its promotion of violent jihad as the solution to a crisis very often depicted by pictures of collusion between various enemy groups), as well as to document and better understand its major chronological evolutions (such as the rise of outgroup pictures in later Rumiyah magazines, or the fall in utopian images of the "Caliphate").

Our paper therefore advances the literature in three ways. Theoretically, it contributes to the literature on extremist propaganda, political violence and intergroup conflict by integrating the role of images in the dynamics of radicalization and communication that these theories propose. This effort may incidentally offer useful insights for research agendas participating in the "aesthetic turn" in IR and security studies (Bleiker 2001), such as visual securitization (e.g. Hansen 2011; Heck \& Schlag 2013) or the impact of particular images on the public opinion / foreign policy nexus (e.g. Gilboa 2005; Caverley \& Krupnikov 2015). Methodologically, this paper tailors generic visual coding methods to the study of images in violent groups' propaganda specifically, paving the way for future research on groups other than IS. Empirically, it strengthens recent scholarship on the study of IS' information warfare, and produces results whose relevance goes beyond the specificities of that group. ${ }^{6}$ Beyond scholarly interest, our paper also provides practitioners with detailed insights on IS' communications, using propaganda as data for the information war front (as suggested by Kydd \& Walter 2006).

\section{The Power of Images: Vectors of Meaning ANd Emotions}

\section{A) Images' narrative power}

\footnotetext{
${ }^{5}$ We do so without embracing "visual determinism" (Domke, Perlmutter \& Spratt 2002), instead circumscribing the multidimensional and sometimes ambiguous effects of images.

${ }^{6}$ Indeed as Gill and colleagues have highlighted (2013), violent groups engage in "malevolent creativity", copying each other's successful innovations.
} 
It is useful to start by drawing on interdisciplinary research outside traditional terrorism studies to inform our theoretical framework for how the meaning attributed to images relates to their narrative power. The literature suggests that "images do not convey meaning in the same way as do texts" (Corrigall-Brown 2012: 132). When it comes to conveying a message, experimental research on drivers of successful advertising demonstrates the superior capacity of pictures and text compared to text alone (e.g. Unnava \& Burnkrant 1991; Babin \& Burns 1997). Combining relevant pictures with text improves learning of and attention to the message, emotional involvement, comprehension, recall, and adherence, especially for poor readers (e.g. Levie \& Lentz 1982; Graber 1996; Houts et al. 2006). Furthermore, images that contain secondary symbolic information (pictorial metaphors) are shown to generate diffuse moral evaluations among individuals regarding what is centrally depicted, either positive (with symbols such as a blue sky, a dove) or negative (with symbols such as lightening) (e.g. McQuarrie \& Phillips 2005).

Images similarly strengthen the messages they accompany in political communication. Scholars have recently stressed the "inter-visual" or "intertextual" dimension of images that are neither simply additions to language nor "free-standing entities, but [...] constituted through spoken and written discourse" (Hansen 2011: 51). Put differently, they "rely on our predisposition to 'see' what they want us to 'see' because of a range of influences that come out of the particular culture and history in which we live" (Petchesky 1987: 268). Visual images in political discourses indeed rarely make sense on their own, but rather further accentuate particular political messages, together constituting broader meaning systems. Visuals can therefore be used more or less tactically to reinforce particular political perceptions and opinions. ${ }^{7}$ Galtung's seminal contribution on "peace journalism" versus "war journalism" $(1986)^{8}$ first showed how different types of images - those depicting conflict versus those featuring dialogue - produce biased perceptions of and attitudes toward a single conflict. A growing number of recent studies have since demonstrated images' "narrative power", i.e. their ability to reflect, crystallize and further disseminate already existing perceptions ${ }^{9}$ through narrow and homogeneous "visual landscapes" that promote very specific interpretations of the depicted issue (Rohlinger \& Klein 2012). ${ }^{10}$ Hansen's work on pictorial "icons" ${ }^{\text {"11 }}$ (2015) further observed that some of these images become symbols of political struggles, thereby producing greater emotional and homogenizing effects when they are strategically articulated to a political message or system of meaning.

\footnotetext{
${ }^{7}$ Corrigall-Brown and Wilkes (2012) warn that news images at times convey ambivalent meanings, where for example two opposing groups are each portrayed in both positive and negative ways, often in a single photograph.

${ }^{8}$ Fahmy and Neumann (2012) offer a recent application of this framework to the 2008-2009 Gaza war.

${ }^{9}$ For example Griffin and Lee's (1995) analysis of the predominance of images of US military might and technological advancement in the American news coverage of the first Gulf War, or Bleiker et al.'s (2013) analysis of the visual depiction of refugees in the Australian press.

${ }^{10}$ As Petchesky notes (1987: 263), "antiabortionists in both the US and Britain have long applied the principle that a picture of a dead fetus is worth a thousand words".

${ }^{11}$ Like the "hooded prisoner" of Abu Ghraib, or the napalm girl of Vietnam.
} 
Images are therefore interpreted in different ways by different groups based on their established worldviews. ${ }^{12}$ As Domke, Perlmutter and Spratt (2002: 131, 147) explain, visuals “influence people's information processing in ways that can be understood only by taking into account individuals' predispositions and values. [...] individuals of course can be persuaded by images, but that one's pre-existing values, cognitions and feeling often play a major role in how images are attended to, interpreted and acted upon”. Hence, the power of images lies less in their ability to directly persuade and more in their ability to accentuate a particular frame and activate pre-existing group-based narratives and appraisals of political events, often in a way that is more effective than the use of language alone.

\section{B) Images' emotional power}

When compared to text or speech, images are thought to be strong drivers of emotions (Hansen 2011: 55; O’Neill et al. 2013: 414). As Dauber and Winkler (2014:9) sum up, images are "more emotionally visceral" than text. Some scholars have further argued that specific images trigger specific emotions that are known to play an important role in political attitudes-for example, images of children elicit different emotional responses and policy preferences than images of soldiers (Caverley \& Krupnikov 2015). This discussion primarily highlights the specific effects of gruesome, graphic visual imagery. Sontag for example suggested that such images "anesthetize" (1977: 20) individuals, thus preventing rather than encouraging political mobilization. ${ }^{13}$ More recent work, however, offer more ambivalent accounts. In their study of anti-abortion and anti-slavery campaigns, Halfmann and Young argue that shocking and gruesome images "produce strong emotions that increase the intensity and emotional resonance of movement frames" (2010: 4), and note that this impact is neither unambiguous nor equally distributed across audiences. While some come to reject the underlying political message by associating it to a feeling of disgust, shock or lassitude, others feel the need to critically evaluate their preexisting beliefs and potentially support the message (Halfmann \& Young 2010).

As stressed above, images never convey meaning on their own: the emotions they elicit depend on the interplay between the characteristics of the image itself and the worldview of the audience. Because an image is necessarily interpreted through the lens of a preexisting worldview, it triggers different emotions among different individuals. In turn, by eliciting particular emotions, images reinforce individuals' existing worldviews in a way similar to the cyclic effect of emotion-laden intergroup speech (Baele, Sterck \& Meur 2016). Particular images can be to "emotionally frame" political issues (Bleiker et al. 2013: 399), and mobilize a target group by eliciting particular emotions that subsequently reinforce the group's worldview by stabilizing its dominant interpretations of the political issue represented by the image. In other words, images reinforce the association between cognition, evaluations, and emotions (Domke, Perlmutter \& Spratt 2002). When it comes to social movements' attempts to attract sympathizers, as Jasper and Poulsen note (1995: 498, 496), symbolic images are sometimes favored as they "capture - both cognitively and emotionally — a range of meanings" that are relevant to potential recruits, "pre-

\footnotetext{
${ }^{12}$ Or, to use Lakoff's terminology (2001), individuals' cognitive "conceptual systems".

${ }^{13}$ See also Moeller's (1999) claims regarding "compassion fatigue".
} 
cisely because these recruits already have certain vision of the world, moral values, political ideologies, and affective attachments".

While single pictures may deliver a significant emotional effect, Jones and Henriksen's study of the impact on viewers' attitudes of an anti-abortion documentary (1987) showed that emotionally-elicited attitude shifts can be short-lived. The potential of visual propaganda to reshape or consolidate worldviews therefore does not simply depend on how images convey emotions, but also rests on their ability to produce what Halperin, Sharvit and Gross (2011) call "long-term sentiments" towards the audience's perceived ingroup and outgroup. This can only be achieved through repetition of a limited visual landscape. Framing efforts are generally known to be more effective when repeated (see e.g. Sieff 2003; Kunda 1999; Chong \& Druckman 2007), and as Baele, Sterck and Meur explain (2016: 725, our emphasis), it is "the recurrence of collectively experienced emotions in response to framed events [that] acts as a powerful mechanism in the confirmation of worldviews (confirming its myths and axioms) and enduring long-term sentiments toward the outgroup, [increasing] the likelihood of a new conflictrelated event".

Emotions are indeed not only known to depend on collective worldviews (Cheung-Blunden \& Blunden 2008b; Halperin, Sharvit \& Gross 2011; Baele, Sterck \& Meur 2016) and appraisal (e.g. Frijda 1986; 1987; 1993; Kuppens et al. 2003), but also to possess specific "action tendencies" (Lazarus 1999: 657; Elster 1996: 1388). The emotions provoked by images can thus at times stimulate action, as already observed (Levie \& Lentz 1982: 219; O’Neill \& Nicholson-Cole 2009; O’Neill et al. 2013). Importantly, for our focus on violent extremist groups' propaganda, several emotions are precisely known to trigger antagonistic action tendencies such as aggressive behavior or violence: anger (e.g. Frijda 1986; 1987; Betancourt \& Blair 1992; Roseman, Wiest \& Swartz 1994; Papps \& O’Carroll 1998; Agnew 2001; Kuppens, Van Mechelen, Smits \& De Boeck 2003; Cheung-Blunden \& Blunden 2008a), but also shame, fear, hatred and resentment (e.g. Ray, Smith \& Wastell 2004; Halperin et al. 2014; Baele 2016). In summary, the repeated diffusion of anger, fear, resentment, or shame-inducing images that resonate within a specific group and strengthen an existing political narrative blaming an outgroup, do not only reinforce the group's long-term sentiments towards the outgroup, but also increase the risk of individual members undertaking corrective actions. Images can also trigger positive emotions (e.g. pride, love, serenity) that can potentially reinforce the audience's affiliation with the ingroup, which is, as Reicher and colleagues (2005) stressed, an important "pull” mechanism in people's support for extremist groups.

\section{Violent Extremists’'Visual Propaganda: A Conceptual Framework}

\section{A) Images in extremist propaganda: Overall logic}

We claim that when it comes to violent extremist groups' communications, visual images' interlocking powers of narration and emotion can potentially reinforce the overall goal of radicalizing distinct audiences in different ways. Understanding radicalization as the dynamic "change in beliefs, feelings, and behaviors in directions that increasingly justify intergroup violence and demand sacrifice in defense of the ingroup" (McCauley \& Moskalen- 
ko 2008: 416), ${ }^{14}$ we argue that images can be used to influence target audiences' attuning to broad intergroup tensions or conflict - a crucial phase of radicalization when personal identities align to the one of the imagined ingroup (Silke 2008: 110; McCauley \& Moskalenko 2008: 426). ${ }^{15}$ Specifically, we suggest that the repeated diffusion of a narrow visual landscape constituted by anger-, fear-, resentment-, or shame-inducing images consolidates positive ingroup identity and negative outgroup identity by solidifying already existing narratives structuring intergroup conflict.

To specify this process further, we build on Ingram's claim (2017) that extremist propaganda promote radicalization by linguistically manipulating ingroup and outgroup identities through the construction of crisis and solution narratives. ${ }^{16}$ Narratives constructing a crisis diagnosis are "characterized by uncertainty, the breakdown of tradition, and the influence of the Other", which operates as a "push" factor in radicalization (Ingram 2017: 359). They seek to provoke negative emotions, for example anger or resentment, and thereby to push individuals to act; as Silke (2008: 114) and Horgan (2008: 85) note, decisions to exert revenge and retribution are usually grounded in feelings of outrage and injustice. ${ }^{17}$ In contrast, narratives constructing a solution prognosis offer feelings of "certainty, reinforcement of tradition, and commitment to the ingroup", thus operating as a "pull" factor in the radicalization process (Ingram 2017: 360). They are usually associated with positive emotions such as pride or hope with the aim to attract potential sympathizers to a positively-valued ingroup. Extremist narratives connect the outgroup(s) with the crisis and the ingroup with the solutions in a "cyclical cognitive reinforcement" process. The repeated connection between outgroups and crisis constructs, and ingroup with solution constructs fortifies group-delineated dichotomous identity structures with push and pull factors to drive radical mobilization. The overall logic of visual propaganda, we argue, is to further strengthen the power of these crisis/solution constructs by inducing emotional reactions that increase the likelihood of radicalization. Through their dual emotional and narrative powers, images are key tools to reinforce exclusive group identities and cement the crisis or solution attributions that fuel radicalization.

\footnotetext{
${ }^{14}$ Radicalization is a hotly contested concept (e.g. O'Loughlin, Boudeau \& Hoskins 2011; Borum 2011; Kundnani 2012; Heath-Kelly 2013) depicting a complex, multifaceted process involving interdependent social and cognitive processes. By focusing on dynamics, we oppose static views in terms of "root causes" of individuals' commitment to political violence (Horgan 2008). As McCauley and Moskalenko show (2011), relevant factors span from individuals' failed adaptation to a new personal life situation, to interpersonal mechanisms of small-group homogenization, to mass-scale inter-group tensions. Radicalization can be slow or, as noted by many observers of IS, remarkably swift (e.g. EUROPOL 2016).

${ }^{15}$ Social Identity approaches to intergroup conflict (following Tajfel \& Turner 1979) also extensively show the correlation between increased group identity salience and group members' propensity to engage in discrimination against individuals perceived as members of another, rival group (for a review see Cairns \& Hewstone 2001). As a person defines or categorizes himself/herself more and more "as the embodiment of a social collective or group" and less "as a separate individual with personal motives, goals, and achievements", he/she is increasingly likely to engage in derogatory behavior against perceived outgroup members, with violence as an extreme outcome when particular contextual conditions are met (Gaertner et al. 2000: 100). As Bar-Tal and colleagues summarize (2012: 41), individuals who strongly identify with a group in conflict come to share a common "ethos of conflict".

${ }^{16}$ This echoes Tugwell's (1986: 6) observation that both "evil and inevitable victory dominate terrorist propaganda".

${ }^{17}$ This argument is also consistent with Betancourt and Blair's claim (1992) that blame attribution and negative emotions are interconnected drivers of hostile attitudes in intergroup conflict.
} 
Yet violent extremists' visual propaganda is not uniform. Rather, we argue that two different logics—one static and one dynamic - are at play. First, each group is characterized by its own visual style, that is, its basic choice of the content and type of narrow visual landscape it tends to favor, providing a static baseline. Second, over time each group then dynamically departs (or conversely narrows down even further) from the established visual style in response to developments on the ground, showing differing degrees of variation in imagery content over time. The remainder of this section provides details on these two logics, whose interplay is crucial for understanding the pull and push of radicalization appeals.

\section{B) Static logic: Extremist groups' visual styles}

The baseline for an analysis of a violent extremist group's visual propaganda is its visual style, which is characterized by the group's usual choices of what its images depict and how. More specifically, we suggest that violent groups' visual styles can be identified by the group's typical choices on four formal characteristics that together determine their images' narrative and emotional powers.

Ingroup or Outgroup: Individuals represented in image. The first characteristic concerns the type of individuals represented in the image, specifically whether the people in the picture are identified as members of the identified ingroup or the outgroup. As Brown and colleagues demonstrated (2005), different emotional dynamics are triggered by the viewing of pictures depicting ingroup members as opposed to outgroup members. Negative visual depictions of the outgroup generate negative emotions such as resentment and anger (e.g. Illustration 1 in Appendix; given the graphic character of some of the supporting illustrations, we have chosen to move all of them to the appendix, section E), thereby promoting negative long-term sentiments towards the outgroup and potentially aggressive action tendencies. On the contrary, positive depictions of the ingroup tend to elicit particular positive emotions (e.g. enthusiasm, joy, pride: see Illustration 2) that reinforce ingroup affiliation and favorable opinions about it. Extremist groups may therefore privilege ingroup and outgroup pictures over ones not clearly representing either. Moreover, pictures may reinforce both out- and ingroup assigned identities through reification, that is, by offering stereotypical visualizations that homogenize them as objectively existing, fully coherent entities with inherent negative/positive traits (Illustrations 1 and 2 both do it). This strategy, well studied in language, ${ }^{18}$ further enhances ingroup favoritism and outgroup animosity.

Narrative connection. The second, related aspect is the type of narrative connection provided by the image. Images that directly reinforce the crisis/solution narratives promoted by an extremist group strengthen its linguistic message, whereas unrelated pictures achieve little. To do so, images represent either the ingroup or the outgroup in ways that evoke a specific narrative. For example, Illustration 1 not only depicts the outgroup in a negative way, it also simultaneously reinforces the Weather Underground's anti-capitalist and anti-racist narrative of the debt crisis. Illustration 3 shows the Muslim ingroup being violently oppressed by the brutal American out-

\footnotetext{
${ }^{18}$ See Reicher and Hopkins' (2001) “eternalization” (claims that the outgroup has engaged in negative behavior against the ingroup for times immemorial) and "psychologization" (claims that all members of the outgroup share, by essence, negative psychological traits).
} 
group, highlighting a crisis narrative while simultaneously depicting an outgroup in a negative way. Conversely, violent extremist groups can also positively represent their own group to further reinforce the positive narratives and frames articulated in their propaganda about themselves - in other words to emphasize their privileged role in the solution to whatever the crisis might be. The association between the ingroup and the solution can reinforce group pride, and encourage people's willingness to sacrifice for the group. As exemplified by Illustration 4, some groups go as far as to embed a caption in their images in order to make the connection with the narrative as evident as possible. These types of narrative-backing images are powerful tools for violent propagandists, as they go beyond the mere visual depiction of friends and enemies by shaping the target audiences' appraisals of a situation or event in a way that triggers negative/positive emotions, further polarizes worldviews, and encourages either "pull" or "push" radicalizing action tendencies.

Shock value of image. The third characteristic concerns the shock value of the image, whether it is gruesome or not. As discussed above, gruesomeness has a unique emotional power: rather than having a universal impact, gruesome images polarize, alienating "uncommitted audiences" while potentially "intensifying the beliefs of the already committed, or newly recruited, and motivate them to act” (Halfmann \& Young 2010: 2). There is already some evidence of such effects in extremist groups' communications. Mika (2006) highlights the importance of shocking images in reinforcing, among potential sympathizers of radical animal rights movements, the moral claims underpinning the narratives that these images sustain. Simultaneously, he warns about potentially unproductive backlash of graphic images against the social movement. Jasper and Poulsen's interviews with members of similar groups (1995: 493) similarly highlighted that "moral shocks in the form of visual or verbal rhetoric" play an outstanding and "necessary" role in their recruitment and desire to act up. We therefore suggest that gruesome images constitute a potentially useful tool to reinforce violent groups' narratives. Illustration 4 provides an example of a gruesome visual montage destined to solidify potentially sympathetic audiences' adherence to the Army of God's narrative of abortion as genocide. Conversely, such imagery is likely to have a counterradicalizing effect on opposing audiences, potentially creating a hostile reaction to the group. Interestingly, in the case of violent groups seeking direct confrontation (as for most Millenial groups), this backlash can be an objective in itself. ${ }^{19}$

Symbolic valence of image. The fourth characteristic concerns the symbolic valence of the image, which we understand as the presence of absence of an "icon", that is, a visual element that condenses group-related meaning (as in Wignell, Tan \& O'Halloran 2017). As noted above, the presence of symbolic elements in an image elicit (positive or negative) evaluations about what is depicted in the image. Icons can therefore potentially maximize the reception of the depicted narratives among sympathetic audiences. Moreover, through repetition and sometimes explicit captions, visual symbols can become direct, condensed representations of a group's specific narratives (Wignell, Tan \& O’Halloran 2017), echoing Lasswell's initial definition of propaganda as the "management of collective attitudes by the manipulation of significant symbols" (1927: 627). O'Shaughnessy concurs: "judi-

\footnotetext{
${ }^{19}$ See McCauley and Moskalenko's (2008; 2011: 149) discussion of provocation strategies (“jujitsu politics”) in radicalization mechanism.
} 
cious choice or manufacturing of symbols and symbolic strategies is an important part of the propagandist's work" (2000: 6). Illustration 5 provides three examples of symbolic visuals used by extremist groups, all taken from the same issue of Jabhat al-Nusra's English-language magazine al-Risalah. The central image in particular symbolizes the ingroup as a wolf, widely known as a strong, powerful, and intelligent animal committed to its group: this image in itself positively represents the ideal ingroup member and therefore contributes to the idea that the ingroup is apt at delivering a solution to the identified crisis. Many symbols are chosen because of their history, in an effort to increase the legitimacy of the group. For example, most Salafi-jihadist groups today make heavy use of the black flag to claim linkage to the Prophet himself (Ostovar 2017) or the Kalashnikov to situate their endeavors as the continuation of the anti-Soviet jihad of the 1980s (Kovacs 2015). Other symbols include animals or natural elements. As explained by Bhui and Ibrahim (2013), recurring symbols do even more than crystallizing particular narratives: they gradually become building blocks in the formation of a genuine group culture, thereby shaping individuals' identities as members of the group.

The interplay between these four characteristics is crucial; visual images in violent extremist group's propaganda are particular combinations of these four aspects. Indeed an image characterized by a specific combination of these characteristics is likely to trigger, among individuals holding particular worldviews, different emotional dynamics and shape social cognition differently than another one characterized by a different combination. We argue that violent extremist groups tend to favor, on average, particular combinations of these four characteristics, i.e. to adopt a specific visual style which corresponds to a preferred propaganda strategy destined to elicit particular effects among the target audience.

\section{C) Dynamic logic: Visual style shifts}

While establishing a violent group's visual style is useful for identifying how the group depicts its message(s), it is also crucial to acknowledge that groups at times modify it, sometimes incrementally sometimes abruptly. Groups may shift their style by increasing, decreasing, or varying the frequency of different types of images over time. For example, a group may increase focus on a different narrative, vary the frequency of gruesome images, or opt to select more images featuring the outgroup. These shifts may be short-lived and the group may return to their common static visual style, or the shift may represent a long-term change in visual strategy. We suggest that visual style shifts result from three kinds of factors: strategic decisions, ideological evolution of the group, or changes in material constraints for the group. These factors usually occur together and are therefore difficult to disentangle, given the opacity of violent extremist groups. However, a better understanding of the dynamics of visual style is crucial in terms of monitoring extremist communications and their likely consequences.

Strategic decisions. The visual landscape of an extremist group's propaganda may change due to strategic decision-making. The strategic paradigm, frequently used in terrorism research, suggests that decisions are made in relation to known external factors to optimize the outcomes of interest for the group (see Kydd \& Walter 2006; Sandler \& Arce 2003; Shapiro 2012). This theoretical perspective has been used to analyze extremist group behavior, such as target or weapon selection (e.g. Jackson \& Frelinger 2008). The logic, however, can be translated 
to explain how groups make strategic decisions in the selection of propaganda imagery to optimize appeal to their perceived ingroup, and influence the outgroup in specific ways that match the group's purposes in a given environment. For instance, as Milton (2016) has shown, IS' propaganda apparatus is bureaucratically organized to ensure harmonization of outputs according to strategically established guidelines about what to communicate and how to do it in order to elicit particular reactions. While this organization arguably constitutes an extreme example, extremist groups do at least try to produce and disseminate potentially efficient communication. Here, we offer two prominent examples.

The first example relates to changes concerning the shock value of images. Groups that find they are alienating an important part of their potentially sympathetic audience with gruesome images may reduce or stop the publication of these images. This issue was a major point of dispute between Al-Qaeda core leadership and Al-Zarqawi when the latter was pursuing a strategy of graphic visual representation of Muslims killing Muslims; in his wellknown 2005 letter, Al-Zawahiri advocated abandoning this practice to prevent the alienation of potential sympathizers. ${ }^{20}$ In contrast, groups may also shift their visual style towards more graphic content to increase their visibility, attract more committed recruit, and elicit violent reactions from their enemies. Abrahms (2008) describes how the use of violence can increase group commitment and encourage recruits because participating in such behavior is dangerous, which increases the social solidarity of participating in the group. Likewise, the depiction of violence and gruesome images may increase if an extremist group identifies a need to increase group cohesion. Decisions to feature or exclude, or vary the frequency of gruesome images are made due to how the group anticipates the audience reaction. For example, IS once stopped the release of a video of a man's hand being chopped off in Raqqa fearing it may provide their opposition with fodder and undermine the group narrative (Farwell 2014). At the same time, images of IS members with kittens multiplied, promoted by the group leadership to emphasize the dual narratives of masculine strength and nurturing comfort. Strategic considerations leading to the inclusion/exclusion of gruesome (and other types of) images can also, moreover, be dictated by the group's will to target several different audiences along linguistic or cultural lines. As Winkler and colleagues (2018) for example showed, IS' use of "images of death and dying” in English and Arabic print publications differed.

The second example relates to the group's favored type of narrative connection. Groups that tend to favor images supporting crisis narratives may strategically shift towards images emphasizing their ability to deliver a solution. For example, a group may differentiate itself from competing groups who are stressing crisis narratives by emphasizing images of their solution. The Northwest Front, for example exclusively use solution and utopia images on its website, with no crisis imagery, whereas the American Nazi Party, a similar group in terms of ideology, features the Nazi symbol almost exclusively. Or these groups may choose to narrow their visual style to depict the crisis with even more accuracy or insistence in order to purposefully exaggerate it in an environment where the crisis becomes less evident among the target audience. Groups may also chose to publish an increasing proportion of negative outgroup images related to their crisis narrative if they want to maximize the likelihood of

\footnotetext{
${ }^{20}$ The letter is available online at https://ctc.usma.edu/posts/zawahiris-letter-to-zarqawi-original-language-2.
} 
spontaneous violent behaviors among their audience; if they wish to elicit attacks in specific states or cities, they may even include symbols of these states or cities.

Material constraints. Second, groups may change their visual style because of new material constraints. Changes in manpower, financial, territorial and security resources can provoke dramatic shifts in a group's capabilities and hence visual style. The assassination or removal of group members may produce a skill deficit for producing and disseminating propaganda material, while the recruitment of skilled persons may increase the number of images in publication, and the type of images available for inclusion in group propaganda. Government bombing of computer facilities may destroy the group's ability to produce modified versions of photos usually engineered to include symbolic elements. Relatedly, groups gaining territory have more opportunities to display photos featuring the ingroup as a positive solution provider, reinforcing solution narratives, while such images become less available as the group loses ground. In sum, the ability for a group to produce and disseminate specific kinds of visual propaganda is inherently related to resources, including control of infrastructure.

Arguably, the internet has produced a new environment with which groups can directly reach a global audience unlike in the past where terrorist groups relied exclusively either on handmade material (see Torres Soriano 2010) or on the media reporting their propaganda by deed, thereby easing material constraints. Yet, although much of the world is now connected with access to the Internet, states can sometimes reduce network access, which in turn could affect groups' abilities to produce and disseminate material, provoking shifts in their visual style. For example, the Iraqi government reduced access by one-third across the country and made efforts to shut down the internet in IS-controlled territory (Farwell 2014). IS subsequently utilized providers in Turkey and Iran (Farwell 2014), which may influence the type of content IS was able and willing to produce. Analyzing group propaganda over time when there were differing degrees of internet access may therefore show different types of content. ${ }^{21}$ Different imagery may be used to target diaspora populations to join or support the group compared to the issues raised to mobilize locals. Changes in territorial control and security, as well as manpower and skill sets can all influence how much visual propaganda is produced, how often, and the type of content depicted in imagery.

Ideological evolution. Changes in visual propaganda might result from an evolution of a group's ideology. Extremist groups' ambitions shift over time such that groups have been described as having "protean political platforms" (Abrahms 2008: 87). For example, Stern (2003) describes Al Qaida's shifting aims from advocating for defensive jihad in Afghanistan against the Russian invasion, to focusing on local struggles in specific conflict zones around the world, and then to the "far enemy." This shift in political aims did not simply follow from strategic considerations, but from an ideological evolution that was reflected in the group propaganda. Changes in ideological focus occur in many groups for tactical, existential, and genuine philosophical reasons and drive visual style shifts.

\footnotetext{
${ }^{21}$ Also depending on whether the group is seeking to address a larger, broader audience or a smaller, local audience.
} 
These shifts may first occur because extremist groups are typically composed of individuals or subgroups with varying ideological sensibilities, some of them more "radical", "pragmatic", or "vanguardist" than others. As these individuals or subgroups gain prominence in the group's apparatus or propaganda system, they may choose to "soften" (or "harden") the visual imagery supporting their communication. They may include (or exclude) more gruesome images, add (or remove) negative depictions of particular out-groups, or introduce new symbols (or remove old ones) to stress a specific ideological idea, or favor specific narratives over others in order to match the newly defined official ideology. Hence, the death or removal of group members may contribute to a shift in group ideology that may then be mirrored in visual propaganda.

\section{Measuring Violent Extremists' Visual Style: the Case of IS}

With this theoretical framework in hand, the next challenge is to develop a robust and replicable method for measuring visual content in extremist propaganda. Political images are notoriously difficult to study in a rigorous way, posing a "significant and so far largely unexplored methodological challenge" (Bleiker 2015: 872). Valuable attempts have recently been made to address this problem; however, they remain either generic (e.g. Schnettler \& Raab 2008; Grady 2008), provide only general (yet important) operational guidelines (e.g. Rose 2012), or offer theoretical discussions on the study of images (e.g. Bleiker 2015). When detailed methodological guidelines are developed, they are tailored for particular types of images (such as political cartoons in Danjoux 2012). This is arguably an inherent limitation of visual analysis and thus we focus specifically on the study of extremist groups' propaganda. Specifically, in order to illustrate the utility of our framework and procedure for measuring visual style, we focus on the case of IS propaganda in two Western facing magazines: Dabiq and Rumiyah.

\section{A) Method}

Our method follows two steps. The first step is to identify from the existing literature the master crisis/solution frames and specific narratives characterizing the ideology of the violent group (in our case-study below, IS) or the broader family of groups it belongs to (in our case again, Islamist groups in general and Salafi-jihadist organizations in particular). Doing so recognizes that frames and narratives derive from the "theorized connection between the image and the broader context in which its meaning is made" (Rose 2012: 91). At the highest level, master frames provide the "central organizing idea for making sense of relevant events and suggesting what is at issue" (Gamson 1989), which in the case of violent extremist groups is usually equivalent to establishing a broad diagnostic of a crisis of unprecedented scale (driven by the outgroup) and presenting the ingroup as the sole possible provider of the solution. Constitutive of master frames, narratives provide the necessary details, offering a "coherent system of interrelated stories and sequentially organized stories that share a common rhetorical desire to resolve a conflict" (Halverson, Goodall \& Corman 2011:14). Whether focusing on master frames or narratives, the categories developed for analysis must be exhaustive, exclusive, and analytically useful for the broader research community (Slater 1993: 236; see also Rose 2012). 
The second step is to develop a suitable protocol for coding images along the four characteristics developed in Conceptual Framework, Section B: the type of individuals represented in the image (binary: members of the ingroup or members of the outgroup ${ }^{22}$, the type of connection between the image and a relevant pre-existing narrative (categorical: link to one of the identified narratives), the emotional strength of the image (binary: gruesome or not) and the symbolic valence of the image (categorical: presence of specific symbols). Given the complexity of our analytical framework, we rely on manual coding of extremist images. ${ }^{23}$ Intercoder reliability must be ensured at the outset (e.g. through an iterated coding procedure on a limited sample) and assessed at the end, although norms of satisfaction with cross-coders coherence inevitably vary between these four characteristics (identifying a gruesome image is more straightforward than identifying a link to a specific narrative).

\section{B) Data}

As already noted, IS' use of visual imagery is not the first instance of an extremist group using pictures to reinforce its communications. Violent groups across the ideological spectrum, from the Weather Underground or the American Nazi Party in the 1960s-1970s to the Army of God or al-Qaeda in the 1990s-2000s, have consistently relied on the power of visual imagery. However, IS has innovated at two levels: first by releasing a staggering quantity of still and moving images, ${ }^{24}$ and second by its highly strategic choice and editing of images, which are an integral part of its broader warfare and political operations (Ingram 2014; 2015; Milton 2016). Many of these images are embedded in magazines and subsequently circulated on social media. More specifically, we analyse images in IS' Dabiq ${ }^{25}$ and Rumiyah ${ }^{26}$ English language propaganda magazines. Dabiq was produced by IS' communication unit in charge of propaganda in non-Arabic languages (al-Hayat Media Center) between mid-2014 and mid-2016 alongside magazines in other languages (French, Russian, Turkish). These magazines were replaced in summer 2016 by Rumiyah magazine, which is (among others) written in English and significantly shorter than past magazines (61 and 45 pages on average respectively). Taken together, Dabiq and Rumiyah occupy a central and pivotal position in IS' propaganda system (e.g. Ingram 2016) - they are the first-line, most easily available outlet providing information in an attractive way that does not require prior knowledge of Arabic or a strong religious education. As Ingram (2016: 2) sums up, Dabiq "offer[s] its readership a powerful 'competitive system of meaning' [...] through which it shapes its readership's perceptions, polarises their support, and drives their radicalisation."

\footnotetext{
${ }^{22}$ There may be images that do not depict or represent either group, which should be coded as a separate "other" category.

${ }^{23}$ While computer-assisted methods for coding images are advancing (e.g. Sonka, Hlavac \& Boyle 2015), we privilege expert coding at this stage because available algorithms cannot reliably code a visual image's connection to a particular narrative and because training computer recognition for a sample of our size would be less efficient than using expert human coders.

${ }^{24}$ By the authors' own count, IS has officially released 1278 unique, fully-edited videos during the 2-year period between December 2014 and January 2017, while Milton (2016) counted 875 videos over 1.5 year (January 2015 to July 2016). According to yet unpublished work from Winter, between October 2014 and October 2015, IS released more than 14500 single photographs and 1787 formally arranged photo reports. Photo reports are quantitatively the most important output of IS propaganda, estimated between 63\% (Zelin 2015) and 78\% (Winter 2015; Winter 2017 arrives at 61\%).

${ }^{25}$ According to the magazine itself, the title Dabiq refers to the eschatological location of "one of the greatest battles between the Muslims and the crusaders" (Dabiq 1: 3).

${ }^{26}$ Rumiyah means Rome, which also carries eschatological symbolism.
} 
We rely on data from all 15 issues of Dabiq magazine (July 2014-July 2016) and all 13 issues of Rumiyah (September 2016-September 2017). Circulated online as high-quality PDFs, Dabiq and Rumiyah magazines contain a substantial number of images: 2058 (1485 in total and 1.6 per page, on average, for Dabiq and 573 in total and 1 per page for Rumiyah). Figure 1 below provides the distribution of these images across time. Illustration 6 in the online Appendix provides examples of cover pages and typical pages of the two magazines.

Overall, Figure 1 demonstrates the ebb and flow of the number of images over time. The first Dabiq issue was heavily visual with over 2.5 pictures per page, but until Dabiq 6 the number of words grew faster than the quantity of images - as the magazines became more voluminous they included approximately the same number of images. Dabiq 7 marks a change, with an increase in the number of images and in terms of their presence per page. The transition to Rumiyah is abrupt in terms of total number of images. This does not only reflects the more compact character of the new publication, but also a shift in the use of images, as the ratio of images per page drops off as well, to low level that then remain relatively consistently across the ensuing issues. In Rumiyah magazines, images are generally larger, taking up more space in the magazine, and many images are repeatedly used across issues than in Dabiq. This, as will be discussed further below, bears the mark of both material constraints and strategic decisions.

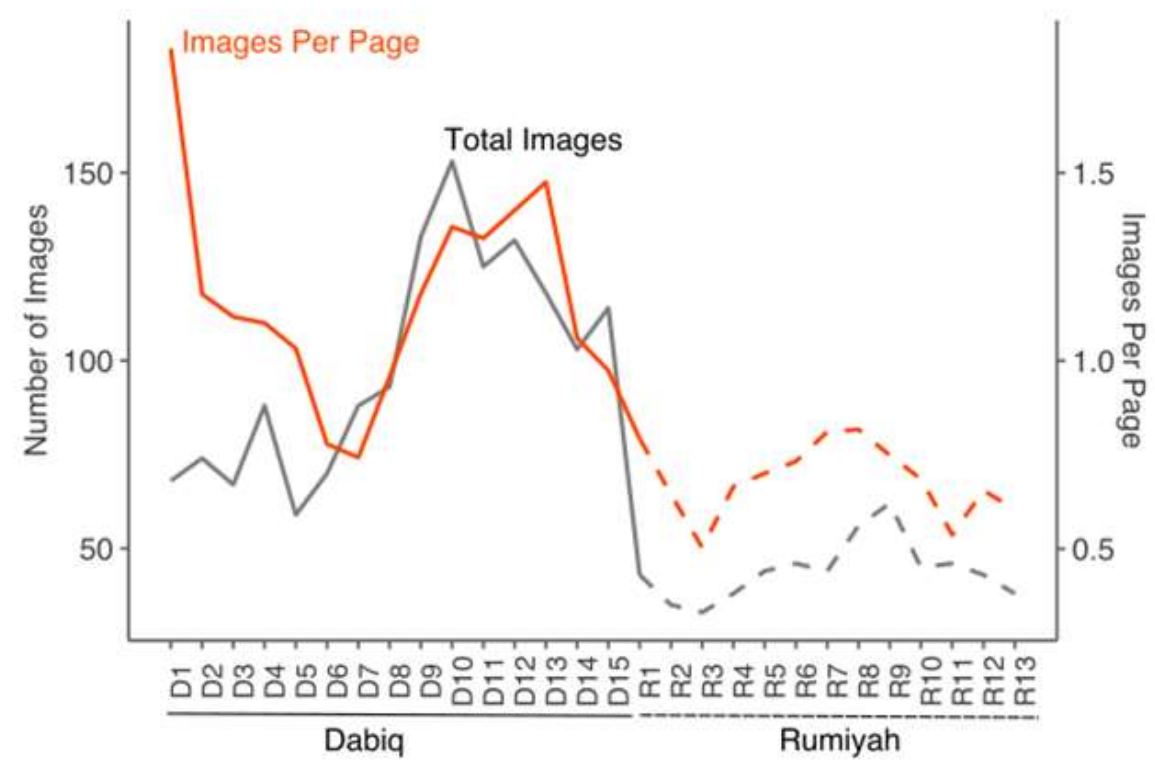

Figure 1: Images across Dabiq and Rumiyah.

\section{C) Step 1: Identifying frames and narratives}

Based on the literature of the worldviews and communication of violent Islamist groups in general and IS in particular, we identified two master frames and eight specific narratives constructing these master frames, in order to prepare the coding of pictures. In terms of master frames, we follow Ingram's analyses of extremist propaganda $(2016$; 2017) as structured by two broad interconnected claims: first the presence of a deep and general corruption of Muslim faith and oppression of Muslims worldwide (crisis provoked by the outgroup), and second the messianic arrival of the Islamic State as the unique, genuine and effective protector of Muslims and Islam (solution pro- 
vided by the ingroup). Ingram explains that this structure channels the construction of the reader's identity to the unambiguously positive version of the Islamic State, restricting both the analysis of complex social problems (such as poverty, inequality, or geopolitics) and the range of solutions available to address these problems (joining the violent action of the Islamic State being the only one). Drawing chiefly on Winter's typology of the major themes present in the Islamic State's communication (2015a; 2015b), we identified eight narratives structuring this twofold framing. The first four relate to the crisis diagnosis, while the last four are associated with the solution prognosis - we provide typical examples of images illustrating these narratives in an online appendix.

In terms of crisis diagnosis, first is the narrative that Muslims are victims of their enemies' evil actions-an oppression that supposedly traces back to the Crusades. Images exemplifying this narrative would show Sunni Muslims who have been injured or killed by Western bombings. Second, the West occupies Islam's holiest places. Given the centrality of this theme in Bin Laden's communications and his high status in IS' discourse in spite of the schism with al-Qaeda, this is a potentially important narrative that would be visually represented by images of US military in the Muslim world. Third, the enemy is profoundly sinful, a corrupt society in moral decay that can only lead to eventual collapse. One potential illustration of this narrative would be of drug addicts or prostitutes in Europe or the US, or of Shi'a religious practices. Fourth, these deviant influences permeate on Muslims' faith and practices, encouraged by outgroup leaders plotting against Islam. Possible examples of this narrative would include pictures of famous Western "moderate Muslim" scholars, or images picturing Arab and "Crusader" leaders shaking hands.

In contrast to crisis diagnosis, previous literature suggests several narratives with a general solution prognosis. First, the Islamic State represents a utopian society, where Islam is practiced at its most perfect form and where as a consequence every aspect of life (health, childcare, economy, etc.) works perfectly. The Islamic State draws on an apocalyptic utopian narrative to market the "caliphate" as an ideal state and community, potentially through images of recreational activities, childcare, well-stocked marketplaces and performing structures of governing bodies. Second, relatedly, unity within IS is absolute: very different Muslims from all over the world work together in perfect harmony and camaraderie to establish the utopian caliphate. Images representing this narrative would feature individuals showing unity in gesture or formation. Winter (2015) and Abrahms (2008) articulate the importance of this theme for the Islamic State to draw in new recruits by appealing to people seeking friendship and belonging to the ingroup. ${ }^{27}$ Third, the Islamic State successfully engages in violent jihad against its enemies, overpowering the opposition. Images of Islamic State's weapons, fighting units or battlefield operations provide evidence of their supposedly military success and supremacy in conflict. The narrative of inevitable success in war, in conjunction with that of victimhood, serves to inspire a sense of duty amongst ingroup members to contribute to a winning cause. We complemented the documentation of this narrative by using a secondary indicator, coding the presence/absence of weapons in the images. Fourth, the Islamic state ruthlessly punishes its enemies

\footnotetext{
${ }^{27}$ Abrahms (2008: 94) generally argues that "the preponderance of evidence is that people participate in terrorist organizations for the social solidarity, not for their political return", and that people join violent groups following a desire for social solidarity, rather than for the political goals associated with that group.
} 
with extreme violence. The Islamic State is indeed well known for images of brutality, which should be understood within the narrative framework that the group is the only one able to react against oppression and issue brutal justice, possessing a "self-proclaimed supremacy and ability to exact revenge on behalf of Sunni Muslims" (Winter 2015: 22). Images of brutality also provokes intimidation and outrage amongst members of the outgroup. ${ }^{28}$ The table below summarizes the 8 narratives.

\begin{tabular}{|l|ll|}
\hline \multicolumn{1}{|c|}{ Crisis diagnosis } & \multicolumn{2}{c|}{ Solution prognosis } \\
\hline 1. Muslims as victims of their enemies' evil ac- & 5. & Islamic State as utopian society. \\
tions. & $6 . \quad$ Absolute unity within IS. \\
2. Western occupation of Islamic land. & $7 . \quad$ IS is successful at jihad. \\
3. Sinful enemy. & $8 . \quad$ IS ruthlessly punishes its enemies. \\
4. Outgroup plot against Islam. & & \\
\hline
\end{tabular}

Table 1: IS' propaganda narratives.

\section{D) Step 2: Coding the four key characteristics of IS'visual style}

Principle. We personally coded all the images from our sample along the four characteristics developed above. The coding scheme is fixed and the group's overall static logic is assessed by analyzing proportions of images representing each of the four characteristics across the whole sample of magazines, while the dynamic logic is analyzed by comparing the proportion of images in each magazine issue. Each image was first coded according to the presence of either ingroup or outgoup members. IS' radical takfiri ideology (read e.g. Bunzel 2015) based on an extreme interpretation of the Islamic concept of al-Wala' 'a' wa al-Baraa' (allegiance to the authentic Islamic group, disavowal of other ones) means that, in their own terms, there is no "grey zone" between those embracing IS' project and those opposed, ambivalent or ignorant of it. IS' outgroup of "unbelievers" (kuffar) is as oversized as it is composite, comprising of the Shi'a, "crusaders" (including Western powers as well as Russia, Japan and other states), "fake" Muslim scholars, and "apostate" "idolatrous" (taghut) regimes. As a consequence, individuals as radical as al-Qaeda leader Ayman al-Zawahiri are identified as enemies by IS, and were coded as such in our database. Second, each image was coded according to the narrative it supported, from the eight abovementioned narratives supporting either a crisis frame or a solution frame to analyse the static and dynamic propaganda goals of IS in English-language magazines. Each image was also coded according to the presence or absence of major jihadist visual symbols, chosen from the works of Ramsay (2013: 65), Kovacs (2015), Ostovar (2017), Bhui and Ibrahim (2013) and Halverson, Goodall and Corman (2011): the black flag, maps, natural landscapes (including outer space), animals (chiefly lions, wolves, eagles, sheep), religious artefacts (e.g. calligraphic Qu'ran page, Kaaba in Mecca) ancient knights or historic characters from the Prophet's times, one of the main elements (fire, water, ice, wood, earth, air). We added the Guantanamo suit, probably IS' original addition to the list of Jihadi visual symbols, totaling eight visual symbols. Finally, we coded each image as either gruesome or not. Although what constitutes gruesomeness can be seen as highly subjective, we stuck by Halfmann and Young's strict understanding of a gruesomeness as grotesque (2010, see above), only coding images as such when

\footnotetext{
${ }^{28}$ Provocation of the outgroup is a well-known strategy in asymmetrical conflict, openly acknowledged by Bin Laden himself. See footnote 19 on McCauley and Moskalenko's (2001) concept of “jujitsu politics".
} 
they elicit an instinctive reaction of disgust, displaying dead corpses, dismembered or beheaded bodies. As a consequence, coding of this aspect proved extremely coherent across coders.

Interrater reliability. With the coding protocol in hand (see section A in the online appendix), two of the authors coded the images for elements of visual style and we assessed interrater reliability to ensure coding was accurate and consistent. Specifically, we followed the standard procedure of quantitative content analysis: the two coders annotated a small sample of images, assessed interrater reliability, discussed disagreements, and finally reached an agreement of the correct coding by committee. For example, to code "Muslim unity in IS" it was specified that a collection of individuals does not satisfy the criteria for this category, but rather the images must have individuals showing unity in gesture or formation; another example of clarification was when an image includes both a member of the in- and outgroup, we specified that the group undertaking the action should be coded. ${ }^{29}$ The final interrater reliability estimates from this procedure are provided in Table 1 below. As demonstrated in the figure, we observe substantial agreement for each of the primary categories under consideration: Cohen's $\kappa$ ranged from 0.95 (ingroup images) to 0.72 (sinful outgroups), with an average agreement of 0.81 . Lastly, we divided the remaining magazines between the coders and conducted another assessment of interrater reliability randomly selecting 5 images per magazine. The coders maintained substantial agreement. ${ }^{30}$

\begin{tabular}{|l|l|l|}
\hline & Cohen's & $\begin{array}{c}\text { Agreement } \\
\text { (proportion) }\end{array}$ \\
\hline Ingroup & 0.95 & 0.97 \\
$\quad$ Symbols & 0.93 & 0.98 \\
$\quad$ Black Flag & 1.00 & 1.00 \\
$\quad$ Cosmo \& landscapes & 1.00 & 1.00 \\
$\quad$ Animal (lion, sheep, etc.) & 1.00 & 1.00 \\
$\quad$ Religious artefact & 1.00 & 1.00 \\
$\quad$ Ancient knights & 0.65 & 0.67 \\
$\quad$ Main element (fire, water, etc.) & --- & --- \\
$\quad$ Gitmo suit & --- & --- \\
Outgroup & --- & --- \\
Gruesome & 0.80 & 0.89 \\
Narratives & 0.79 & 0.98 \\
$\quad$ Muslim Unity in IS & 0.76 & 0.81 \\
\hline
\end{tabular}

\footnotetext{
${ }^{29}$ Most coding categories in fact did not need agreement by committee. Such a procedure was first and foremost needed for the narrative code, primarily because some recurring types of images tend to participate in a narrative, but in indirect ways or "weak" ways. As a result, during the first round of coding, the two coders at times disagreed whether these images did in fact strengthen a narrative (and tended not to disagree on which narratives these images reinforced). Much of the committee agreement work thus focused on the minimal strength that an image needs to have with a narrative.

${ }^{30}$ Unfortunately, there was still lower agreement while coding narratives. However, a close investigation of the inconsistencies did not include any cases where one annotator coded a crisis narrative and the coded solution narrative - rather, and further illustrating the difficulty exposed in the previous footnote, the discrepancy in coding was mainly due to one coder's caution preferring to code no narrative, while the other coder was more liberal with coding the narratives. We clarified the operationalization of the narratives further and reviewed all the narrative coding to ensure consistency.
} 


\begin{tabular}{|l|l|l|}
\hline IS Issues Justice & 0.85 & 0.86 \\
Caliphate Utopia & 0.80 & 0.95 \\
Muslims as Victims & 0.80 & 0.89 \\
Violent Jihad & 0.74 & 0.79 \\
Outgroup Plot & 0.73 & 0.76 \\
Sinful Outgroups & 0.72 & 0.73 \\
\hline
\end{tabular}

Table 2: Interrater reliability across categories (bold) and sub-categories (italics). ${ }^{31}$

Estimated measurement error for coder classifications. Quantitative measures derived from the coded images are subject to error. Although the estimated reliabilities presented in Figure 2 are acceptable by traditional standards, recent scholarship in political science (Grimmer, King, and Superti 2015) and communication (Bachi and Schar-kow 2017) highlights the necessity of accounting for the uncertainty associated with imperfect agreement. To adjust our subsequent empirical analysis for potential coding errors, we estimate measurement uncertainty using a simple Bayesian model, which draws inspiration from the Bayesian misclassification modeling literature originally developed in biostatistics (Prescott and Garthwaite, 2002; McGlothlin, Stamey, and Seaman, 2008). Briefly, our model 1) combines information on the proportion of agreement between our two expert coders (see Table 1) with informative priors to offer an estimate of the uncertainty associated with (potential) coding errors (see online appendix section B for full details on the model specification and estimation). As demonstrated below, the inclusion of measurement error does little to change our substantive findings on the prevalence of solution and crisis narratives in IS visual propaganda.

\section{E) Analysis: Measuring IS'visual style.}

We present and discuss our results in the remaining paragraphs, highlighting the key dimensions of IS' visual style and studying their chronological variations, considering the three factors potentially playing a role in such shifts and discussing the implications of this style on radicalization and intergroup polarization.

Type of individuals visually represented. In terms of overall group representation, the overwhelming majority of images in Dabiq and Rumiyah unambiguously show ingroup or outgroup members (1733 images or 90\%, with the remaining images often being landscapes). This almost exclusive focus on the ingroup and its outgroup is a central component of IS' visual style, and mirrors what is known about extremist language. Of these images, $41 \%$ depict the outgroup while $59 \%$ show members of the ingroup $;^{32}$ Figure 2 (a) shows the proportion of images depicting the in- and outgroups across the magazines, unveiling two main findings. First, IS' propaganda generally favors the visual depiction of the ingroup, representing another long-lasting aspect of its visual style. Nonetheless, this aspect seems to have waned over time, first incrementally and then abruptly. Figure 2(a) shows that

\footnotetext{
${ }^{31}$ Note that random sample to calculate reliability did not include any instances of the "ancient knight", "main element," and "Gitmo suit" symbols and thus Cohen's kand agreement are undefined. This does not constitute a problem, as these symbols are unambiguous and very easy to spot.

${ }^{32}$ There are differences in the use of in- and outgroup images across these two magazines. For example, over $91 \%$ of images in Dabiq clearly designate the in or outgroup, compared to only $84 \%$ of images in Rumiyah. Of these images, a greater proportion of images depict the ingroup in Dabiq compared to Rumiyah (60\%, 54\%, respectively).
} 
Dabiq magazines depicted more ingroup images than outgroup in all but two later issues (Dabiqs 13 and 14). In contrast, in Rumiyah the preference for in and outgroup images fluctuates, suggesting an alternating focus; of the 10 Rumiyah issues four have more images of the outgroup than the ingroup (issues 3, 5, 9, and 10). Interestingly, the issues with more images of the outgroup feature articles about "evil scholars" ${ }^{33}$ Although "evil scholars" is a phrase used in some of the other issues, the propaganda evolved to showcase this topic in articles thus featuring more imagery of outgroup members.

While there are a number of potential explanations for the shift towards depicting the outgroup, it is likely due to a combination of strategic considerations and material constraints. As shown in Online Appendix C, Dabiq 13 was issued in January 2016 when the caliphate was at its largest; the territory decreased in size rather continuously since then at the very same time that the group stopped favoring ingroup over outgroup images. The loss of territory encouraged the group to make a strategic decision to combat competing ideology (hence the focus on "evil scholars") and reinforce anger or resentment towards the outgroup (rather than positive emotions associated with the ingroup) as the fight intensified. This shift also reflects - and further precipitates — the group's changing strategy of inciting terrorist actions in the West rather attracting new foreign fighters to the caliphate following the loss of its control of the Syria-Turkey border in September-October 2016.

\footnotetext{
${ }^{33}$ Dabiq 13 and 14 feature articles titled "Kill the Imams of Kuffar" and "Kill the Imams of Kufr in the West". Similarly, Rumiyah 1, 3, 5, and 9 feature articles titled "The Wicked Scholars are Cursed", "The Obligation of Exposing Wicked Scholars", "Traits of the Evil Scholars", and "They Took their Scribes and Monks as Lords Besides Allah".
} 
(a) Ingroup vs. Outgroup

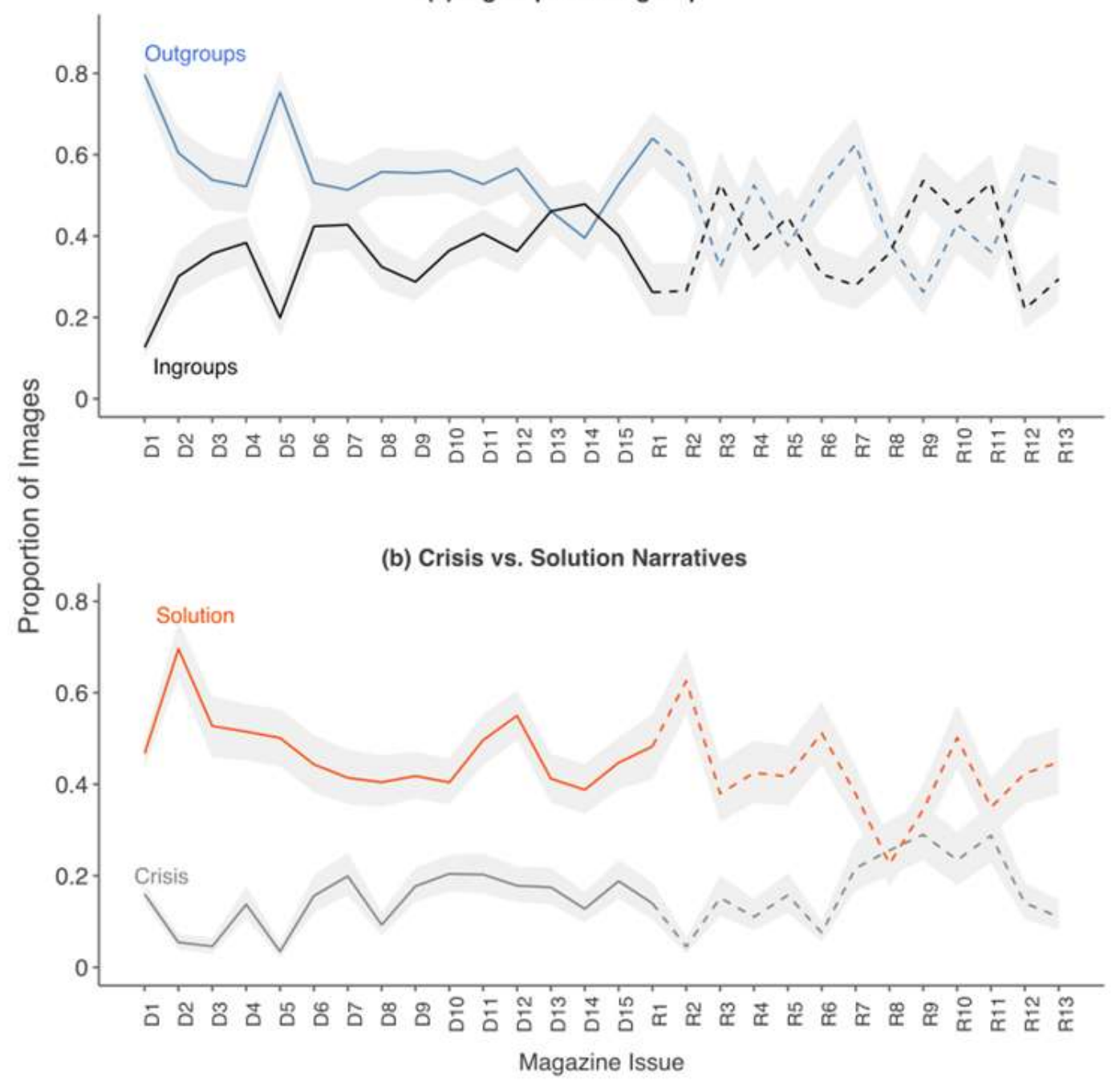

Figure 2: Groups and core master-frames in images over time. Sub-plot (a) presents the percentage of images including an ingroup (black) or outgroup (blue) overtime, while sub-plot (b) plots whether an image employs a solution (orange) or crisis (dark grey) master-frame. The solid line represents images in Dabiq, while the broken line represents Rumiyah magazine. Ninety-percent credible intervals (light grey shading) represent estimated uncertainty due to measurement error.

Type of narrative. The prominence of the ingroup in IS images is consistent with the organization's choice of the narratives: overall IS' propaganda favored images constructing solution-building narratives (45\%, against only $16 \%$ of images constituting the crisis mater frame), ${ }^{34}$ where ingroup members are positively presented in sometimes highly reified ways (see Figure 2(b)) that aim at triggering positive emotions. 68\% of solution images show the ingroup and $28 \%$ depict the outgroup, while $89 \%$ of the crisis frame images depict the various outgroups deemed responsible for Muslim suffering. The majority of images associating the ingroup with solution narratives suits IS' message that they are the sole group able to justly fight against their enemies (the solution-related images with the outgroup depicted are most frequently images of enemies being targeted or killed by IS in combat). Fig-

\footnotetext{
${ }^{34}$ Across the entire sample, 746 images (almost 39\%) did not depict a specific narrative. The proportion of these images differ across issues, with Dabiq 8 and Rumiyah 9 having less than 50\% of the images depicting a narrative.
} 
ure $2 b$ above shows that the use of images to depict the solution master frame has been consistently high across magazines, denoting another key trait of IS' visual style: the group insists, even in moments of crisis, that it is able to deliver the solution. Only one issue, Rumiyah 8, had more crisis-related images; this issue was released four months into the prolonged battle for Mosul, which arguably made crisis-related images difficult to avoid. Illustrations 7 to 14 in the online Appendix E are typical examples of each narratives.

Specifically, from the four narratives constituting the solution prognosis, the claim that IS is effectively carrying out violent jihad far exceeds the other narratives (see Figure 3). ${ }^{35}$ These images make up $26 \%$ of the total images in these magazines, compared to $10.5 \%$ of the images depicting outgroup collusion, making jihad by far the most common narrative. Violent jihad, moreover, outnumber all other narratives in each of the 25 magazines analyzed. Weapons, such as machine guns, knives, swords, and rocket-launchers, are commonly found in images with no less than $36 \%$ of the total images including a weapon. This is remarkably consistent across Dabiq and Rumiyah (36\% and 37\% respectively). This predominance creates a narrow visual landscape typical of IS, as demonstrated in Figure 3 below. Although violent jihad images are a consistent theme in IS propaganda, these images occurred less when the group was enjoying easy successes in the battlefield, and became prominent as the group fought first to consolidate its gains and then to avoid territorial depletion (such images exceed $35 \%$ in 4 of the 10 issues of Rumiyah, compared to 2 of the 15 Dabiq). Of the remaining solution-constituting narratives, images of the utopian caliphate were most frequently used in the Dabiq magazines, when the caliphate was at its peak, then their number gradually dropped off as IS lost territory. Rumiyah 7 saw a short-lived increase in the proportion of these images during the battle for Mosul, an important stronghold IS lost soon after. Similarly, images of IS issuing justice in its territory (what El Damanhoury and Winkler 2018 call "law and order" pictures) became less and less frequent (not featuring in 3 of the 10 Rumiyah), a trend also observed for pictures representing group unity in IS (4 Rumiyah magazines in a row do not include any images of this narrative). We therefore observe a visual style shift characterized by a narrowing of the visual landscape towards violent jihad images and away from positive images of the caliphate as an efficient (in terms of law and order) and utopian place. This shift clearly results from increasingly difficult material constraints afflicting the group as it lost territory and engaged in direct conflict. At the same time original images representing a well-functioning "caliphate" became increasingly hard to justify practically speaking, audiences needed increased reassurance that jihad was still successfully implemented. Yet also valuable to point out is that at the end of August - beginning of September 2016, two important figures in IS' propaganda apparatus were killed: Abu Muhammad al-Adnani, IS' notorious senior leader and spokesperson, as well as Wael Adel Salman al-Fayad (also known as Abu Muhammed Furqan), senior leader in charge of the group's communications and in particular its propaganda videos. These changes at the highest level of the propaganda system correspond with the arrival of Rumiyah, suggesting there may have been a strategic and/or ideological shift in visual imagery.

\footnotetext{
${ }^{35}$ A figure depicting the proportion of narratives with uncertainty is provided online in Appendix, section C.
} 
Images supporting crisis-constituting narratives are a minority (311 images), but they nonetheless significantly shape IS' propaganda visual style by contributing to a narrow visual landscape. Indeed, as shown in Figure 3 below, one crisis narrative - that of an outgroup collusion - is overwhelmingly privileged: it is used almost four times more than the next frequent narrative, the sinful outgroup. In comparison, visual depictions of Muslim victims and Western occupation in Muslim lands are only used infrequently, quite surprisingly given the prominence of these narratives in some of the most well-known non-visual contribution to Salafi-jihadi propaganda, including Bin Laden's interviews. There are only 11 images of Western forces in Muslims lands (less than $1 \%$ of the total crisis images). This insistence on an outgroup conspiracy, which has the potential to elicit resentment and anger, is a key and original constitutive component of IS' visual style.
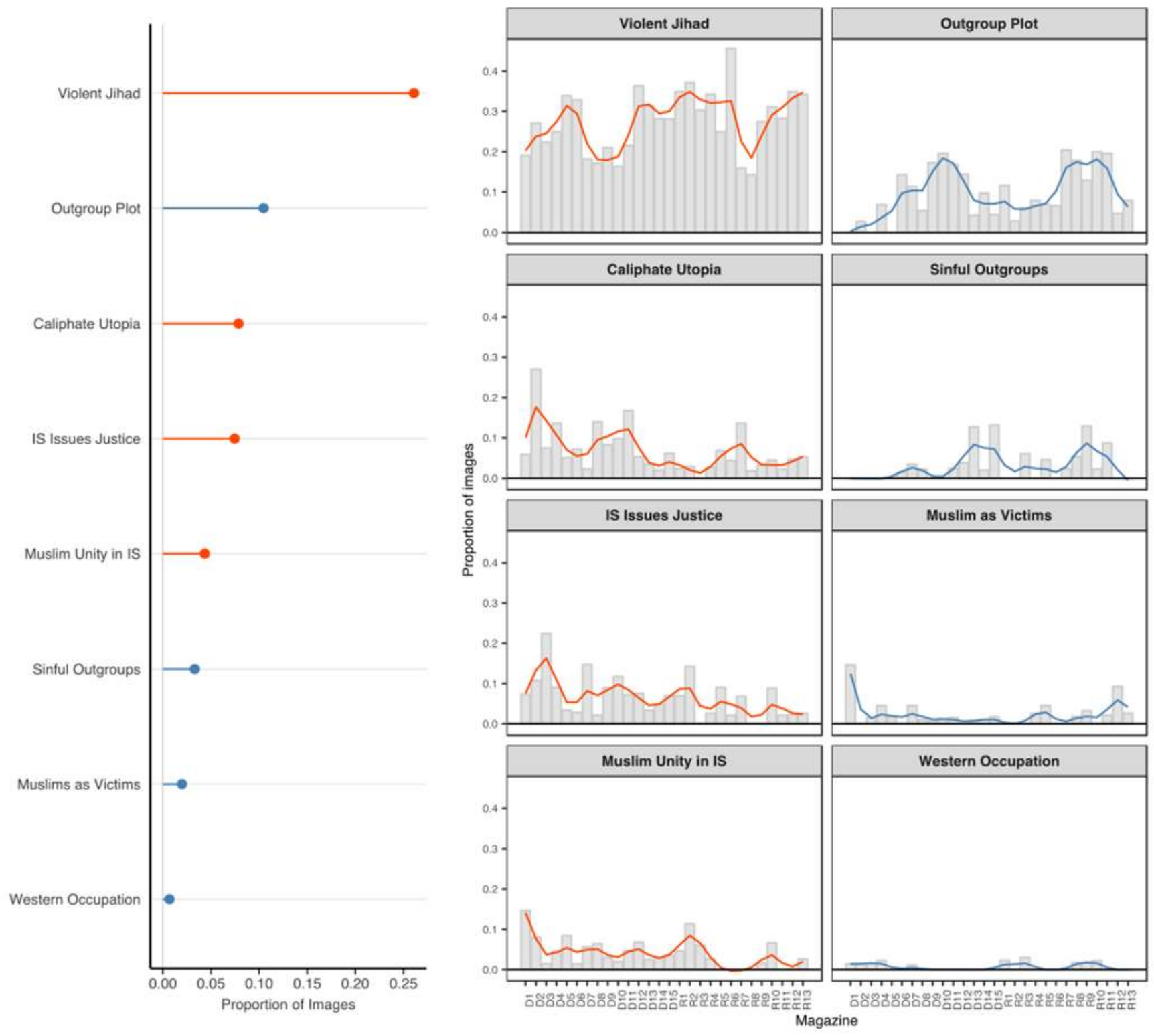

Figure 3: Type of narratives. Left: This figure provides the overall proportion of images including relevant solution (orange) and crisis (blue) narratives across all Dabiq and Rumiyah magazines. Right: The estimated proportion for each narrative over time. We plot the estimated proportion (grey bar) and the cubic spline for solution (orange line) and crisis (blue line) narratives in order to 
provide an overall sense of the trend over time. As demonstrated in the figure, violent jihad is far and away the dominate solution narrative in IS images and generally stable over time.

Looking at the proportion of images depicting each of the four crisis narratives in a chronological way across issues highlights significant shifts in emphasis, suggesting dynamic adjustments of their visual style. Chiefly, we observe a rise of the outgroup plot narrative at the detriment of the initially prominent Muslim victimhood one. We indeed see that the first Dabiq featured Muslims as victims in significantly greater proportion than any of the other crisis narratives (almost 15\%, compared to 1.5\% for West occupation, and $0 \%$ for sinful outgroups and outgroup collusion). Yet across all subsequent issues, images of Muslim victims are never used more than another crisis narrative, and never more than $5 \%$ of the images in any issue. In contrast, images of outgroup collusion plotting against Muslims became much more common, having the greatest proportion of images among crisis narratives in 20 of the 25 issues. This rise stops with Dabiq 11 (September 2015), which corresponds to the start of the group's continuous territorial decline, during which Dabiq 12, 13 and 14 published less and less images supporting this crisis narrative, insisting more on pictures of the violent jihad solution. The Rumiyah magazines then re-shift the focus on the outgroup plot as the battle for Mosul prolongs. Images of the sinful outgroup are not prevalent until Dabiq 13, with the first 5 issues not including any images of this category. It is thus striking to observe that outgroup plot images were favored during the expansion of the group and then again during its most challenging period, suggesting either a lack of strategic consistency or/and the impact of the abovementioned losses at the top of the propaganda apparatus. Nonetheless, overall the group has clearly opted for a specific strategy of heavy repetition of a very narrow crisis-constituting visual landscape, eschewing more classical narratives such as direct oppression of Muslims and US/Jewish occupation of Muslim lands in favor of a more original construction of a crisis constituted by complex plotting networks involving world leaders and (more or less) moderate Islamic scholars.

Symbolic valence of images. Figure 4 shows that a considerable proportion of images contain an icon, evidencing an explicit effort to enrich the visual message, which is another trait of IS' visual style. However, the inclusion of symbols has varied across time. The proportion of images with symbols has fluctuated across issues with a peak in Dabiq 1 followed by a regular decline until symbols become more frequent again from the latest Dabiq, peaking in Rumiyah 2. Of the symbols coded, the black flag is by far the most frequently found in images in these IS magazines, followed by religious artefacts and the Guantanamo suit. Importantly, the black flag was most frequent in the initial Dabiq issue with over $33 \%$ of the images including the flag, and then featured consistently less until Dabiq 15 where it increased in use, peaking again in Rumiyah $2 .^{36}$ IS' over-use of the prime symbol of the "state" when the group launched its magazine in a context of rapid expansion and when it replaced it with a new one in a context of setbacks, reflects these two defining moments in the group's history when it was more crucial than usual to strongly affirm IS' reality and brand, its statehood character, and the legitimacy of its project.

\footnotetext{
${ }^{36}$ Figure 4 clearly shows the impact of the black flag prominence on the overall frequency of visual symbols.
} 
Maps and images of natural elements also display a clear chronological trend, increasing to be found much more frequently in Rumiyah issues. Images of cosmos and landscapes, as well as ancient knight symbols follow similar, though less dramatic trends being found more frequently in Rumiyah. IS' increasing use of such generic images clearly corresponds with its loss of resources and territory, evidencing a diminished ability to efficiently collect and use real quality photos from the various provinces of the caliphate. This contention is reinforced by our observation that many images are repeated across issues of Rumiyah. In contrast, the Guantanamo suit, used in images showing IS preparing or inflicting punishment, is used inconsistently in images across Dabiq and Rumiyah magazines. For example, this symbol is featured most in Dabiq 7 (over $9 \%$ of the images) while the following issue has no image with it. While images of punishment feature most in Dabiq 3, 7, and Rumiyah 2, however, the suit is only prevalent in Dabiq 7 and Rumiyah 2, echoing a strategic decision to feature this symbol with this narrative.

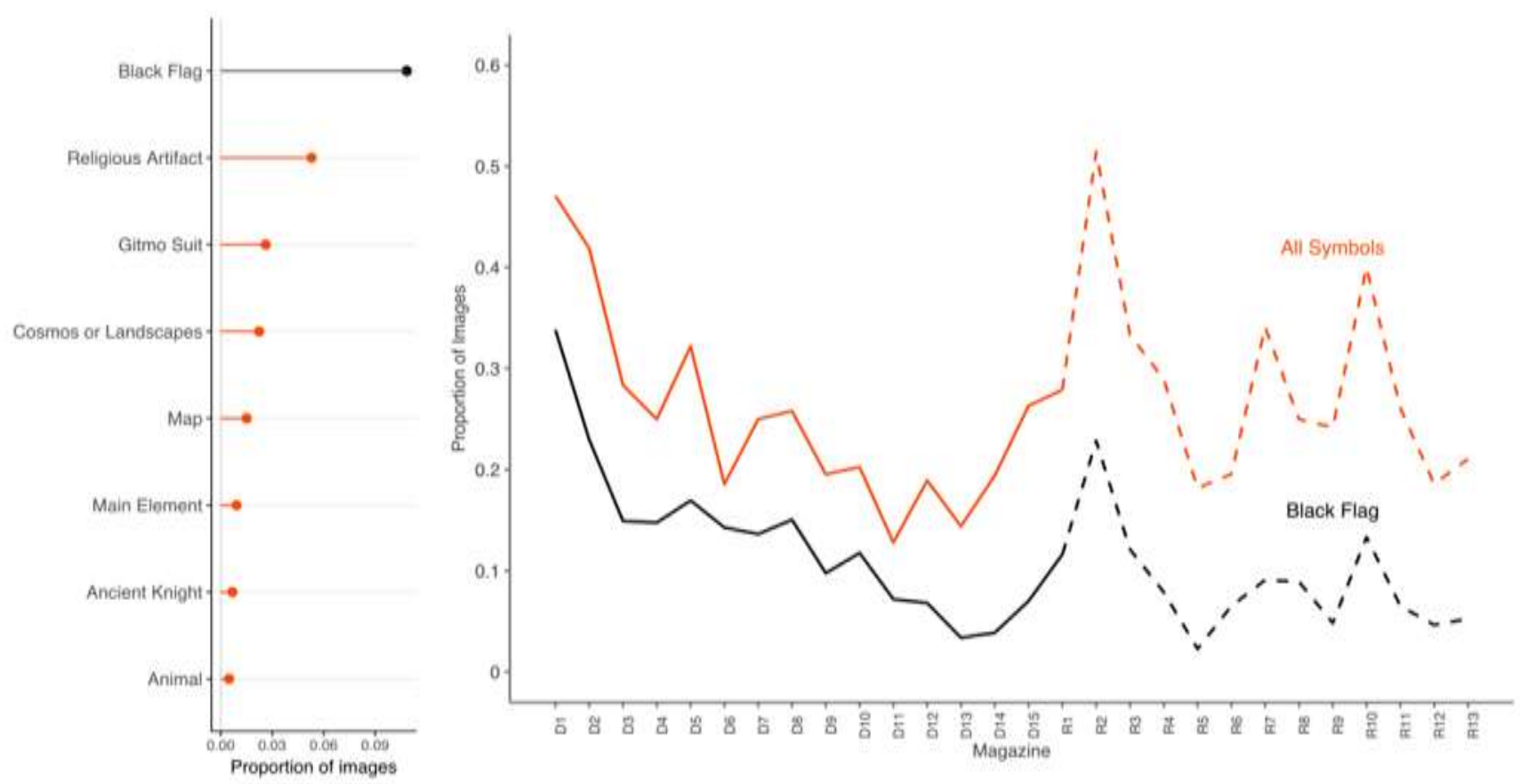

Figure 4: Symbols in Dabiq and Rumiyah. Left: This figure plots the overall proportion of images across all magazines in the sample. Right: This figure plots the variation in the use of symbols over time. The solid line represents images in Dabiq, while the broken line represents Rumiyah magazine.

Shock value of images. Finally, while IS is particularly famed for its use of graphic violence in propaganda videos, there are relatively few gruesome images in the 25 magazines (136, 7\%). These images are used in comparable proportion (6.6\% of the images in Dabiq and $8.5 \%$ in Rumiyah), hence constituting a minor yet recurring dimension of IS' visual style. This component is directly inherited from al-Zarkawi's early communication strategy aimed at polarizing audiences, but it is also an important way to evidence the group's success in two of its solution narratives: IS' ability to ruthlessly punish its enemies, including powerful ones (for example pictures of American victims) and the "enemy within" involved in corruption (for example pictures of executioners cutting thieves' hands), and the jihad narrative (images of victims of their attacks). Seventy-eight percent of the gruesome 
images are associated with these two solution narratives, in comparison to $15 \%$ associated with Muslim victims, predominantly in the first issue of Dabiq. Displaying graphic images constitutes the evidence that the group is efficient in delivering the solution, in contrast with less successful or more compromising - and therefore corrupt - rival groups. Figure 5 shows, however, that the use of such images fluctuates across issues, with $20 \%$ of Rumiyah 2 images being gruesome and none in Rumiyah 8. Given the fact that gruesome images are a well-known component of IS' visual style, and that spikes in online interest in IS (Google searches, Twitter) correspond to the group's use of particularly gruesome videos (chiefly the beheading of James Foley and the burning of the Jordanian pilot Muath al-Kasasbeh) (Davulcu 2018), this variation in the group's use of such images is surprising: it suggests that there is no clear tactical line on when to increase or decrease their numbers, that no internal ideological evolution has shaped their dissemination, and that material constraints did not impact their use. Perhaps given the polarizing nature of gruesome images, the group made a strategic decision to consistently fluctuate the use of gruesome images because consistent frequent use may compromise the appeal of IS to the target audience.

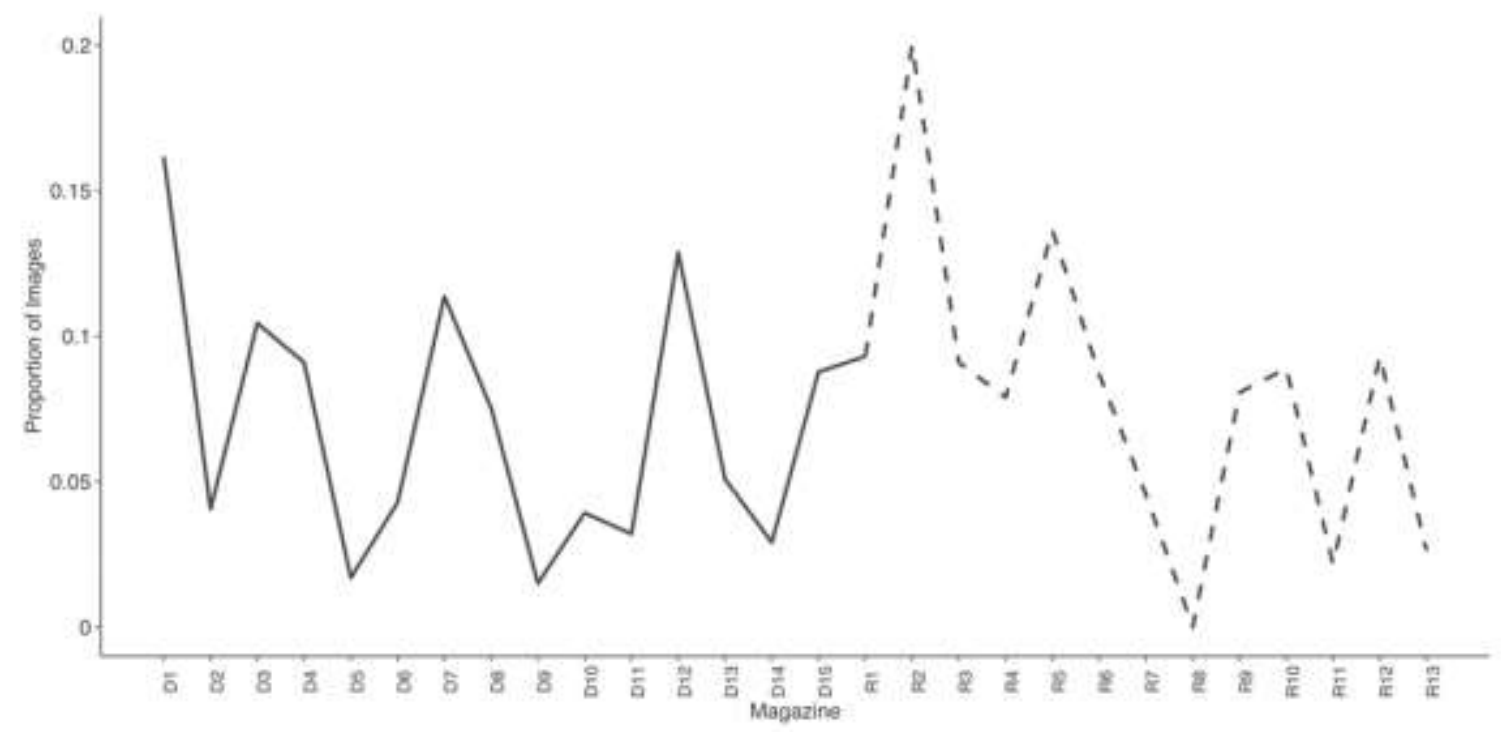

Figure 5: Gruesome images in Dabiq and Rumiyah over time. This figure provides the proportion of gruesome images across our sample of magazines. The solid line represents images in Dabiq, while the broken line represents Rumiyah magazines.

In sum, IS' visual style appears to be characterized by a high proportion of images clearly representing either the ingroup or the outgroup, with a strong emphasis on the ingroup in Dabiq. These images primarily evidence the group's ability to provide a solution, especially through warfare, yet also recurrently represent an outgroup plot. These findings correspond to Ingram's (2017) observations that the linguistic content of IS magazines focuses more on solution narratives than rival Salafi-Jihadi publications like al-Qaeda's Inspire magazines. A significant amount of pictures contain a symbolic element, most prominently the black flag, and gruesome images are irregularly included in the propaganda. There is evidence for an impact of each of the three factors driving visual style 
shifts, although this evidence is qualitative at this stage and in need of further study. ${ }^{37}$ Future research would be needed to investigate which of these three theorized mechanisms best explains specific changes in imagery.

\section{CONCLUSIONS}

This paper provided a conceptual framework and operational guidelines for the study of the visual component of extremist propaganda. Conceptualizing images in political communication as vectors of both meaning and emotions, we put forward the concept of visual style to characterize the fact that different extremist groups may tend to favor different types of images. More precisely, the type of individuals represented in images, the type of narrative connections, the shock value of images and their symbolic valence may tend to differ across groups. We also suggested that three types of factors can provoke visual style shifts: strategic decisions, ideological evolutions and changes in material constraints. Using this methodology to analyze imagery used in IS' Western-facing magazines, we defined the group's visual style and highlighted its major shifts, demonstrating how our framework and method can be used to track changes in visual propaganda strategy over time.

While the empirical results of this study are limited to the images used in IS' English-language, Westernfacing propaganda (further study may reveal that different narratives are featured in the propaganda imagery used to target different audiences), ${ }^{38}$ they nonetheless show interesting findings in the general consistency of the organization's visual landscape, in particular how few images depict crisis narratives present in other similar groups' propaganda (such as Western presence in Islamic lands). The solution narratives prioritized by IS are intended to evoke pride for the ingroup, rather than anger, resentment, fear and shame that may be associated with crisis narrative images. While future research is needed to evaluate the exact relationship between emotion-invoking crisis and solution imagery and action tendencies, it already appears that IS' preference for solution imagery, rather than crisis imagery, has contributed to the remarkable ability IS had recruiting people from around the world to join the "Caliphate". In September 2015 it was estimated that 30,000 foreign fighters had joined IS (Schmitt \& Sengupta 2015), and although the "Caliphate" has now been territorially defeated, for the most part, IS remains a threat around the world as the group shifted strategies to promote violence targeting the "far enemy" with "just terror" articles providing information on how to carry out attacks effectively. Future research should investigate how effective IS's visual propaganda remains without the "Caliphate" and military victories.

\footnotetext{
${ }^{37} \mathrm{We}$ carried out a preliminary examination to quantitatively locate trends in imagery following similar types of events (leadership loss, major airstrike, loss of major city), but this effort falls outside the scope of the current paper. In brief, we coded the issues for whether there was an increase (1) or a decrease (0) in proportion of images for each narrative (and gruesome) and examined Fisher's Exact Test on the contingency table (small sample size). The analysis shows that magazines issued after a leader is killed are associated with a decrease in images of the utopian caliphate $(p=0.06)$, offering some preliminary evidence that some of IS' propaganda narratives may be affected by material constraints, ideological evolution, or strategic decision-making following events IS faces in battle. However, the respective influence of these factors and the exact causal mechanisms involved are hard to precisely isolate without using more accurate and comprehensive information on the conflict.

${ }^{38}$ For instance, El Damanhouri (2017) documented the difference in the type of images disseminated by IS' various provinces.
} 
Our hope is that our approach paves the way for a better understanding of extremist groups' communications beyond the case of IS, and contributes to uniting the field of extremist visual communication studies. More research building on the strengths and limitations of our work is needed along several lines. First, comparative efforts examining differences in visual styles across extremist groups can bring important insights on extremist groups' identities, strategies, and relative positioning within their ideological and political environment. Second, in-depth analysis and systematic monitoring of extremist groups' visual propaganda can bring potentially important insights to security and intelligence practitioners. Third, initiatives could assess, in a near future, the imitation effects that will inevitably occur as various extremist groups will try to learn from IS' success in communications, adopting and adapting IS' visual style to their own audiences and for their own purposes (on "malevolent learning”, read Gill et al. 2013). Fourth, future research should investigate if there are different effects (e.g. emotional, action tendencies, etc.) to the various combinations of elements in an image. For example, gruesome images of violence suffered by the ingroup may have a distinct effect from gruesome images of violence inflicted by the group. Additionally, we call for more research on how the static and dynamic logics guiding extremist groups' visual styles connect with the language with which these groups convey their messages. Combining visual and linguistic analyses in full-spectrum studies of particular groups could provide valuable information to scholars and government experts alike. Beyond the realm of research on extremist propaganda, our research opens up avenues for work on the visual dimension of international security broadly speaking: from the role of positive emotions and narratives in enhancing support for violence, to the use of symbols in establishing a group culture that encourages conflict, much remains to be documented and theorized.

\section{REFERENCES}

Abrahms, M. (2008) “What Terrorists Really Want: Terrorist Motives and Counterterrorism Strategy", International Security 32(4): 78-105.

Babin L., Burns A. (1997) "Effects of Print Ad Pictures and Copy Containing Instructions to Imagine on Mental Imagery That Mediates Attitudes", Journal of Advertising 26(3): 33-44.

Bachl M., Scharkow M. (2017) "Correcting Measurement Error in Content Analysis", Communication Methods \& Measures 11(2): 87-104

Baele S. (2016) "Lone-Actor Terrorists' Emotions and Cognition: An Evaluation beyond Stereotypes", Political Psychology, online before print.

Baele S., Sterck O., Meur E. (2016): "Theorizing and Measuring Emotions in Conflict. The Case of the 2011 Palestinian Statehood Bid", Journal of Conflict Resolution 60(4).

Baines P., O’Shaughnessy N., Moloney K., Richards B., Butler S., Gill M. (2010) "The Dark Side of Political Marketing. Islamist Propaganda, Reversal Theory and British Muslims", European Journal of Marketing 44(3/4): 478-495.

Barthes R. (196) "Le Message Photographique”, Communications 1(1): 127-138.

Betancourt H., Blair I. (1992) "A Cognition (Attribution)-Emotion Model of Violence in Conflict Situations", Personality \& Social Psychology Bulletin 18(3): 343-350.

Bleiker R. (2001) "The Aesthetic Turn in International Political Theory", Millennium: Journal of International Studies 30(3): 509-533.

Bleiker R. (2015) "Pluralist Methods for Visual Global Politics", Millennium: Journal of International Studies 43(3): 872-890. 
Bleiker R., Campbell D., Hutchison E., Nicholson X. (2013) “The Visual Dehumanisation of Refugees”, Australian Journal of Political Science 48(4): 398-416.

Borum R. (2011) "Rethinking Radicalization”, Journal of Strategic Security 4(4): 1-6.

Brown L., Bradley M., Lang P. (2006) "Affective Reactions to Pictures of Ingroup and Outgroup Members", Biological Psychology 71: 303-311.

Boussalis C., Coan T. (2015) "Tracing the Narrative of Hate in the Rising Greek Far-Right", GPSG Working Papers 23, available at http://www.gpsg.org.uk/wp-content/uploads/2015/12/Working Paper 23.pdf.

Bueno de Mesquita E., Dickson E. (2007) "The Propaganda of the Deed: Terrorism, Counterterrorism, and Mobilization", American Journal of Political Science 51(2): 364-381.

Bunzel C. (2015) "From Paper State to Caliphate: The Ideology of the Islamic State", The Brookings Project on U.S. Relations with the Islamic World Analysis Paper 19.

Carrabine E. (2011) "Images of torture: Culture, politics and power", Crime Media Culture 7(1): 5-30.

Caverley J., Krupnikov Y. (2015) “Aiming at Doves: Experimental Evidence of Military Images' Political Effects", Journal of Conflict Resolution, online before print.

Cheung-Blunden V., Blunden B. (2008a) "The Emotional Construal of War: Anger, Fear, and the Other Negative Emotions", Peace \& Conflict 14(2): 123-150.

Cheung-Blunden V., Blunden B. (2008b) "Paving the Road to War with Group Membership, Appraisal Antecedents, and Anger", Aggressive Behavior 34: 175-189.

Chong D., Druckman J. (2007) "Framing Theory", Annual Review of Political Science 10: 103-126.

Corrigall-Brown C. (2012) "The Power of Pictures: Images of Politics and Protest", American Behavioral Scientist 56(2): 131-134.

Corrigall-Brown C., Wilkes R. (2012) "Picturing Protest: The Visual Framing of Collective Action by First Nations in Canada", American Behavioral Scientist 56(2) 223-243

Dauber C. (2014) “The Branding of Violent Jihadism". In Winkler C., Dauber C. (eds.) Visual Propaganda and Extremism in the Online Environment. Carlisle: US Army War College, pp.137-163.

Davulcu H. (2018) "New Analytics for Measuring and Countering Social Influence and Persuasion of Extremist Groups", Arizona State University Working Paper.

Domke D., Perlmutter D., Spratt M. (2002) “The Primes of our Times? An Examination of the 'Power' of Visual Images", Journalism 3(2): 131-159.

Dauber C., Winkler C. (2014) "Radical Visual Propaganda in the Online Environment: An Introduction". In Winkler C., Dauber C. (eds.) Visual Propaganda and Extremism in the Online Environment. Carlisle: US Army War College, pp.1-30.

El Damanhoury K. (2017) "Understanding ISIS's Provincial Propaganda: A Visual Framing Analysis of Wilayat Sinai's Imagery in 2016", Journal of Middle East Media, online before print,

El Damanhoury K., Winkler C. (2018) "Picturing Law and Order: a visual analysis of ISIS's Dabiq Magazine", Journal of Arab Media \& Society 25: 1-20.

Elster J. (1996) "Rationality and the Emotions", Economic Journal 106: 1386-1397.

EUROPOL (2016) Changes in modus operandi of Islamic State terrorist attacks. Review held by experts from Member States and Europol on 29 November and 1 December 2015. Available at https://www.europol.europa.eu/publications-documents/changes-in-modus-operandi-of-islamic-state-terroristattacks.

Fahmy S., Neumann R. (2012) 'Shooting War Or Peace Photographs? An Examination of Newswires' Coverage of the Conflict in Gaza (2008-2009)", American Behavioral Scientist 56(2): NP1-NP26.

Farwell, J. P. (2014) “The Media Strategy of ISIS”, Survival 56(6): 49-55.

Friis S. M. (2015) “'Beyond Anything We Have Ever Seen’: Beheading Videos and the Visibility of Violence in the War against ISIS", International Affairs 91(4): 725-746.

Frijda N. (1986) The emotions. Cambridge: Cambridge University Press.

Frijda N. (1987) "Emotion, Cognitive Structure, and Action Tendency”, Cognition \& Emotion, 1, 115-143.

Frijda N. (1993) "The Place of Appraisal in Emotion", Cognition \& Emotion, 7, 357-387.

Gaertner S., et al. (2000): "Reducing Intergroup Conflict: From Superordinate Goals to Decategorization, Recategorization, and Mutual Differentiation", Group Dynamics: Theory, Research, \& Practice 4 (1): 98-114.

Galtung J. (1986) "On the Role of the Media in Worldwide Security and Peace". In Varis T. (ed.) Peace and Communication. San Jose: ULP Press. 
Gamson W., Croteau D., Hoynes W., Sasson T. (1992) "Media Images and the Social Construction of Reality", Annual Review of Sociology 18: 373-393.

Gilboa E. (2005) "Global Television News and Foreign Policy: Debating the CNN Effect", International Studies Perspectives 6(3): 325-341.

Gill P., Horgan J., Hunter S., Cuhenbery L. (2013) "Malevolent Creativity in Terrorist Organizations", Journal of Creative Behavior 47(2): 125-151.

Graber D. (1996) "Say It with Pictures", Annals of the American Academy of Political and Social Science 546: 85-96.

Grady J. (2008) "Visual Research at the Crossroads", Forum: Qualitative Social Research 9(3): online.

Griffin M., Lee J. (1995) "Picturing the Gulf War: Constructing an Image of War in Time, Newsweek, and U.S. News \& World Report”, Journalism \& Mass Communication Quarterly 72 (4): 813-825.

Grimmer J., King G., Superti C. (2015) "The Unreliability of Measures of Intercoder Reliability, and What to Do About It", retrieved from http://stanford.edu/ jgrimmer/Handbib.pdf

Halfmann D., Young M. (2010) "War Pictures: The Grotesque as a Mobilizing Tactic", Mobilization: An International Quarterly 15(1): 1-24

Halperin E., Sharvit K., Gross J. (2011) "Emotion and Emotion Regulation in Intergroup Conflict: An Appraisalbased Framework", in Bar-Tal D. (ed.) Intergroup Conflicts and Their Resolution. A Social Psychological Perspective. New York: Psychology Press.

Halverson J., Goodall H., Corman S. (2011) Master Narratives of Islamist Extremism. New York: Palgrave Macmillan.

Hansen L. (2011) "Theorizing the Image for Security Studies: Visual Securitization and the Muhammad Cartoon Crisis", European Journal of International Relations 17(1): 51-74.

Hansen L. (2015) "How Images Make World Politics: International Icons and the Case of Abu Ghraib", Review of International Studies 41: 263-288.

Heath-Kelly C. (2013) "Counter-Terrorism and the Counterfactual: Producing the 'Radicalisation' Discourse and the UK PREVENT Strategy", British Journal of Politics \& International Relations 15(3): 394-415.

Heck A., Schlag G. (2013) "Securitizing images: The female body and the war in Afghanistan", European Journal of International Relations 19(4): 891-913.

Hewstone M., Cairns E. (2001) "Social Psychology and Intergroup Conflict”, in Chirot \& Seligman (eds.): Ethnopolitical Warfare: Causes, Consequences, and Possible Solutions. Washington DC: American Psychological Association, pp.319-342.

Horgan J. (2008) "From Profiles to Pathways and Roots to Routes: Perspectives from Psychology on Radicalization into Terrorism", Annals of the American Academy of Political and Social Science 618(1): 80-94.

Houts P., Doak C., Doak L., Loscalzo M. (2006) "The Role of Pictures in Improving Health Communication: A Review of Research on Attention, Comprehension, Recall, and Adherence", Patient Education and Counseling 61: 173-190.

Ingram H. (2014) "Three Traits of the Islamic State's Information Warfare”, RUSI Journal 159(6): 4-11.

Ingram H. (2015) "The Strategic Logic of Islamic State Information Operations", Australian Journal of International Affairs 69(6): 729-752.

Ingram H. (2016) “An Analysis of Islamic State's Dabiq Magazine”, Australian Journal of Political Science 51(3): 458-477.

Ingram H. (2017) “An Analysis of Inspire and Dabiq: Lessons from AQAP and Islamic State's Propaganda War", Studies in Conflict \& Terrorism 40(5): 357-375.

Jackson, B.A., Frelinger, D.R. (2008) 'Rifling Through the Terrorists' Arsenal: Exploring Groups' Weapon Choices and Technology Strategies", Studies in Conflict \& Terrorism 31(7): 583-604.

Jasper J., Poulsen J. (1995) "Recruiting Strangers and Friends: Moral Shocks and Social Networks in Animal Rights and Anti-Nuclear Protests", Social Problems 42(4): 493-512.

Jones H., Henriksen L. (1987) “The Impact of the 'Scream': To Use or Not to Use”, Health Education 18(1): 911.

Kellner D. (2007) “Jean Baudrillard". Stanford Encyclopedia of Philosophy, available at http://plato.stanford.edu/entries/baudrillard/.

Kovacs A. (2015) "The "New Jihadists" and the Visual Turn from al Qa'ida to ISIL / ISIS / Da'ish", Biztpol Affairs 2(3): 47-70. 
Kunda Z. (1999) Social Cognition. Making Sense of People. Cambridge, MA: MIT Press.

Kundnani A. (2012) "Radicalisation: The Journey of a Concept", Race \& Class 54(2): 3-25.

Kuppens P., Van Mechelen I., Smits D., De Boeck P. (2003) "The Appraisal Basis of Anger: Specificity, Necessity, and Sufficiency of Components", Emotion 3(3): 254-269.

Kydd, A.H., Walter, B.F. (2006) “The Strategies of Terrorism”, International Security 31(1): 49-80.

Lakoff G. (2001) Moral Politics. Chicago: University of Chicago Press.

Lasswell H. (1927) "The Theory of Political Propaganda", American Political Science Review 21(3): 627-631.

Lazarus R. (1999) "Hope: An Emotion and a Vital Coping Resource Against Despair", Social Research 66(2): 653-678.

Levie H., Lentz R. (1982) “Effects of Text Illustrations: A Review of Research, Educational Technology Research and Development 30(4): 195-232.

McCauley C., Moskalenko S. (2008) "Mechanisms of Political Radicalization: Pathways Toward Terrorism", Terrorism \& Political Violence 20(3): 415-433.

McCauley C., Moskalenko S. (2011) Friction. How Radicalization Happens to Them and Us. Oxford: Oxford University Press.

McGlothlin A., Stamey J., Seaman J. (2008) "Binary Regression with Misclassified Response and Covariate Subject to Measurement Error: a Bayesian Approach", Biometrical Journal 50(1): 123-134.

McQuarrie E., Phillips B. (2005) "Indirect Persuasion in Advertising: How Consumers Process Metaphors Presented in Pictures and Words", Journal of Advertising 34(2): 7-20.

Mika M. (2006) "Framing the Issue: Religion, Secular Ethics and the Case of Animal Rights Mobilization", Social Forces 85(2): 915-941.

Milton D. (2016) "Communication Breakdown: Unraveling the Islamic State's Media Efforts", Combatting Terrorism Center at West Point, online document available at https://ctc.usma.edu/posts/communicationbreakdown-unraveling-the-islamic-states-media-efforts.

Moeller S. (1999) Compassion Fatigue: How the Media Sell Disease, Famine, War and Death. New York: Routledge.

O'Loughlin B., Boudeau C., Hoskins A. (2011) "Distancing the Extraordinary: Audience Understandings of Discourses of 'Radicalization"', Continuum 25(2): 153-164.

O’Neill S., Nicholson-Cole S. (2009) “"Fear Won't Do It'. Promoting Positive Engagement With Climate Change Through Visual and Iconic Representations", Science Communication 30(3): 355-379.

O’Neill S., Boykoff M., Niemeyer S., Day S. (2013) "On the use of imagery for climate change engagement", Global Environmental Change 23: 413-421.

O’Shaughnessy N. (2000) Politics and Propaganda: Weapons of Mass Seduction. Manchester: Manchester University Press.

Papps B., O'Carroll R. (1998) "Extremes of Self-esteem and Narcissism and the Experience and Expression of Anger and Aggression", Aggressive Behavior 24(6): 421-438.

Petchesky R. (1987) "Fetal Images: The Power of Visual Culture in the Politics of Reproduction", Feminist Studies 13(2): 263-292.

${ }^{1}$ Prescott G., Garthwaite P. (2002) "A Simple Bayesian Analysis of Misclassified Binary Data with Validation Substudy", Biometrics 58(2): 454-458.

Ramsay G. (2013) Jihadi Culture on the World Wide Web. London: Bloomsbury.

Ray L., Smith D., Wastell L. (2004) "Shame, Rage and Racist Violence", British Journal of Criminology 44(3): 350-368.

Reicher S., Hopkins N. (2001) "Psychology and the End of History: A Critique and a Proposal for the Psychology of Social Categorization", Political Psychology 22(2): 383-407.

Reicher S., Hopkins N., Levine M., Rath R. (2005) "Entrepreneurs of Hate and Entrepreneurs of Solidarity: Social Identity as a Basis for Mass Communication", International Review of the Red Cross 87(860): 621-637.

Rohlinger D., Klein J. (2012) "Visual Landscapes and the Abortion Issue", American Behavioral Scientist 56(2): 172-188.

Rose G. (2012) Visual Methodologies. An Introduction to Researching with Visual Materials. Third Edition. New York: Sage.

Sandler, T., Arce M., D.G. (2003). “Terrorism \& Game Theory”, Simulation \& Gaming 34(3): 319-337. 
Schmitt E., Sengupta S. (September 2015) "Thousands Enter Syria to Join ISIS Despite Global Efforts," The New York Times, online available at: https://www.nytimes.com/2015/09/27/world/middleeast/thousands-enter-syriato-join-isis-despite-global-efforts.html.

Shapiro, J. N. (2012) "Terrorist Decision-Making: Insights from Economics and Political Science", Perspectives on Terrorism 6(4-5): 5-20.

Silke A. (2008) "Holy Warriors Exploring the Psychological Processes of Jihadi Radicalization", European Journal of Criminology 5(1): 99-123.

Schnettler B., Raab J. (2008) "Interpretive Visual Analysis. Developments, State of the Art and Pending Problems", Forum: Qualitative Social Research 9(3): online.

Sonka M., Hlavac V., Boyle R. (2015) Image Processing, Analysis, and Machine Vision. Fourth Edition. Stamford CT: CENGAGE Learning.

Sontag S. (1977) On Photography. London: Penguin.

Stern, J. (2003). "The Protean Enemy," Foreign Affairs 82(4): 1.

Tajfel H., Turner J. (1979) "An Integrative Theory of Intergroup Conflict”. In Austin W., Worschel S. (eds.) The Social Psychology of Intergroup Relations. Monterey: Brooks.

Torres Soriano M. (2010) "The Road to Media Jihad: The Propaganda Actions of Al Qaeda in the Islamic Maghreb", Terrorism \& Political Violence 23(1): 72-88.

Tugwell, M. (1986) "Terrorism and Propaganda: Problem and Response", Journal of Conflict Quarterly 6(2): 515.

Unnava R., Burnkrant R. (1991) "An Imagery-Processing View of the Role of Pictures in Print Advertisements", Journal of Marketing Research 28(2): 226-231.

Vergani M., Bliuc A-M. (2015) “The Evolution of the ISIS' Language: A Quantitative Analysis of the Language of the First Year of Dabiq Magazine", Sicurezza, Terrorismo e Societa 2: 7-20.

Waltman M. (2014) "The Role of Internet Visual Imagery in the Radicalizaiton of White Ethno-Terrorists in the United States". In Winkler C., Dauber C. (eds.) Visual Propaganda and Extremism in the Online Environment. Carlisle: US Army War College, pp.83-103.

Wignell P., Tan S., O’Halloran K. (2017) "Violent Extremism and Iconisation: Commanding Good and Forbidding Evil?”, Critical Discourse Studies 14(1): 1-22.

Wignell P., Tan S., O'Halloran K., Lange R. (2017) “A Mixed Methods Empirical Examination of Changes in Emphasis and Style in the Extremist Magazines Dabiq and Rumiyah", Perspectives on Terrorism 11(2): 2-20.

Winkler C., Dauber C. (eds.) Visual Propaganda and Extremism in the Online Environment. Carlisle: US Army War College.

Winkler C., El Damanhoury K., Dicker A., Lemieux A. (2016) "The Medium is Terrorism: Transformation of the About to Die Trope in Dabiq", Terrorism \& Political Violence, online before print.

Winkler C., El Damanhoury K., Dicker A., Lemieux A. (2018) "Images of Death and Dying in ISIS Media: A Comparison of English and Arabic Print Publications", Media, War \& Conflict, online before print, doi.org/10.1177/1750635217746200.

Winter C. (2015a) “The Virtual 'Caliphate': Understanding Islamic State's Propaganda Strategy”, Quilliam Foundation Working Papers July 2015.

Winter C. (2015b) "Documenting the Virtual 'Caliphate"”, Quilliam Foundation Working Papers October 2015.

Winter C. (2017) "The ISIS Propaganda Decline", ICSR Insight, online document available at http://icsr.info/2017/03/icsr-insight-isis-propaganda-decline/.

Zelin A. (2015) "Picture or it Didn't Happen: A Snapshot of the Islamic State's Official Media Output", Perspectives on Terrorism 9(4): 85-97. 